RECEIVED

\author{
JAN 301996 \\ OSTI
}

Detection of Localized

and General Corrosion

of Mild Steel in

Simulated Defense

Nuclear Waste Solutions

Using Electrochemical

Noise Analysis

Prepared for the U.S. Department of Energy

Assistant Secretary for Environmental Management

(28) Westinghouse
Hanford Company Richland, Washington

Management and Operations Contractor for the

U.S. Department of Energy under Contract DE-AC06-87RL10930

Copyright License By acceptance of this article, the publisher and/or recipient acknowledges the

U.S. Governmont's right to retain a nonexclusivo, royalty-freo liconso in ond to any copyright covering this paper.

Approved for public release; distribution is unlimited as

DISTRIBUTION OF THIS DOCUMENT IS UNLIMATED 
LEGAL DISCLAIMER

This report was prepared as an account of work sponsored by an agency of the United States Government. Neither the

United States Government nor any agency thereof, nor any of their employees, nor any of their contractors, subcontractors or their employees, makes any warranty, express or implied, or assumes any legal liability or responsibility for the accuracy, completeness, or any third party's use or the results of such use of any information, apparatus, product, or process disclosed, or represents that its use would not infringe privately owned rights. Reference herein to any specific commercial product, process, or service by trade name, tredemark, manufacturer, or otherwise, does not necessarily constitute or imply its endorsement, recommendation, or favoring by the United States Government or any agency thereof or its contractors or subcontractors. The views and opinions of authors expressed herein do not necessarily state or reflect those of the United States Government or any agency thereof.

This report has been reproduced from the best available copy.

Printed in the United States of America

DISCLM-2.CHP (1-91) 


\title{
Detection of Localized and General Corrosion of Mild Steel in Simulated Defense Nuclear Waste Solutions Using Electrochemical Noise Analysis
}

\author{
G. L. Edgemon \\ P. C. Ohl
}

Westinghouse Hanford Company

G. E. C. Bell

M. J. Schiff \& Associates, Inc.

D. F. Wilson

Lockheed Marietta Energy Systems

Date Published

December 1995

To Be Presented at NACE CORROSION/96

March 24-29, 1995

Denver, Colorado

To Be Published in

Corrosion

Prepared for the U.S. Department of Energy

Assistant Secretary for Environmental Management

$\begin{array}{ll}\text { Westinghouse } & \text { P.O Box } 1970 \\ \text { Hanford Company } & \text { Richland, Washington }\end{array}$

Management and Operations Contractor for the

U.S. Department of Energy under Contract DE-AC06-87RL10930

Copyright License By acceptance of this article, the publisher and/or recipient acknowledges the

U.S. Government's right to retain a nonexclusivo, royaty-freo licenso in and to any copyright covering this paper.

Approved for public release; distribution is unlimited 


\author{
Detection of Localized and General Comosion of Mild Steel in \\ Simulated Defense Nuclear Waste Solutions \\ Using Electrochemical Noise Analysis
}

G. L. Edgemon and P.C. Ohl .

Westinghouse Hanford Company

P. O. Box 1970, MSIN: R1-30

Richland, Washington 99352

\title{
G. E. C. Bell
}

M. J. Schiff \& Associates, Inc.

1291 North Indian Hill Boulevard

Claremont, California 91711-3897

D. F. Wilson

Lockheed Marietta Energy Systems

Oak Ridge National Laboratory

P. O. Box 2008

Oak Ridge, Tennessee 37831-6156

\begin{abstract}
Underground waste tanks fabricated from mild steel store more than 60 million gallons of radioactive waste from 50 years of weapons production. Leaks are suspected in a significant number of tanks. The probable modes of corrosion failures are reported to be localized corrosion (e.g. nitrate stress corrosion cracking and pitting). The use of electrochemical noise (EN) for the monitoring and detection of localized corrosion processes has received considerable attention and application over the last several years. Proof of principle laboratory tests were conducted to verify the capability of EN evaluation to detect localized corrosion and to compare the predictions of general corrosion obtained from EN with those derived from other sources. Simple, pre-fabricated flat and U-bend specimens of steel alloys A516-Grade 60 (UNS K02100) and A537-CL1 (UNS K02400) were immersed in temperature controlled simulated waste solutions. The simulated waste solution was either $5 \mathrm{M} \mathrm{NaNO}_{3}$ with $0.3 \mathrm{M} \mathrm{NaOH}$ at $90^{\circ} \mathrm{C}$ or $11 \mathrm{M} \mathrm{NaNO}_{3}$ with $0.15 \mathrm{M} \mathrm{NaOH}$ at $95^{\circ} \mathrm{C}$.

The electrochemical noise activity from the specimens was monitored and recorded for periods ranging between 140 and 240 hours. At the end of each test period, the specimens were metallographically examined to correlate EN data with corrosion damage.
\end{abstract}


electrochemical noise, localized corrosion, pitting, nuclear waste tank corrosion, mild steel, nitrates, corrosion surveillance, and corrosion monitoring.

\section{INTRODUCTION AND BACKGROUND}

The Hanford Site has 177 underground waste tanks which store approximately 253 million liters of radioactive waste from 50 years of weapons production'. Twenty-eight (28) of the tanks are double-shell and were constructed of welded ASTM A537-Cl 1 (UNS K02400), A515 (UNS K03101), or A516-Grade 60 (UNS K02100) material. The inner tanks of the double shell tanks (DST) were stress relieved following fabrication. One hundred and forty-nine (149) of the tanks are a single-shell design and are made primarily of welded ASTM A283, Grade C material. The single shell tanks were not stress relieved following fabrication. Tank waste is in liquid, solid and sludge forms. Tanks'also contain a moist vapor space above the solid and liquid waste regions. The composition of the waste varies from tank to tank, but, in general terms, has a high $\mathrm{pH}$ $(>12)$ and contains nitrates and nitrites and other minor constituents resulting from plutonium separation processes ${ }^{1-4}$.

Leaks began to appear in the single-shell tanks shortly after the introduction of untreated nitrate based wastes in the 1950's. Leaks are now suspected to be present in a significant number of the single-shell tanks which were not stress-relieved after welding and fabrication ${ }^{2}$. The probable modes of corrosion failures are localized corrosion, in particular, nitrate stress corrosion cracking and pitting ${ }^{2}$.

Previous efforts to monitor internal corrosion of waste tank systems have included linear polarization resistance (LPR) and electrical resistance (ER) techniques ${ }^{5-6}$. These techniques are effective in monitoring general corrosion, but are not suited for detection of localized corrosion. The use of electrochemical noise for monitoring waste tank corrosion was investigated by the Savannah River Site, but the results from these tests were not conclusive?.

For many years, EN has been observed during corrosion and other electrochemical reactions and the phenomenon is wellestablished $^{8-19}$. It has been reported elsewhere that electrochemical noise evaluation is well suited for monitoring and identifying localized corrosion, and for the measurement of general corrosion rates ${ }^{14-20}$. Typically, EN consists of low frequency $(<1 \mathrm{~Hz})$ and amplitude $\left(0.1 \mu \mathrm{V}-10 \mathrm{mV}\right.$ and $10 \mathrm{nA} / \mathrm{cm}^{2}$ to $\left.10 \mu \mathrm{A} / \mathrm{cm}^{2}\right)$ signals which are spontaneously generated by electrochemical reactions occurring at corroding or other surfaces ${ }^{20}$. The use of electrochemical noise for the monitoring and detection of localized corrosion processes, in particular, has received considerable attention and plant application in recent years $^{21-27}$.

The EN evaluation approach involves the monitoring of instantaneous fluctuations in corrosion current and corrosion potential between nominally identical electrodes of the material of interest in the environment of interest. Time-dependent fluctuations in corrosion current are described by electrochemical current noise (ECN), while time-dependent fluctuations of corrosion potential are described by electrochemical potential noise (EPN). The most straight forward method involves simple statistical examination of the temporal records with detailed investigation of identified regions of interest. Other methods of analysis involve transformation of temporal data to the frequency domain for analysis ${ }^{28}$. Each type of localized corrosion phenomenon presents a unique relationship between ECN and EPN transients, thereby allowing distinction between different types of localized corrosion (e.g. pitting, stress corrosion cracking, intergranular attack, etc.).

\section{TEST EQUIPMENT, MATERIALS, AND PROCEDURES}

Electrochemical Noise Equipment

The electrochemical instrumentation consisted of a multi-technique integrated electrochemical corrosion monitoring system manufactured by Capcis March Lid. with the associated software used for data collection and processing. The system was controlled by an IBM(l) compatible computer through an IEEE-488 standard interface and included a multiplexer which allowed sequential data collection on up to 12 channels. The system included electrochemical noise signal processing modules, linear polarization modules for LPR measurements, and a frequency response analyzer with an electrochemical interface for conducting electrochemical impedance measurements.

(1) Registered trademark of International Business Machines, Inc. 
- Data from the EN tests were collected using the DENIS ${ }^{(2)}$ software. The EN equipment was programmed to measure and record ECN and EPN at one second intervals for 512 seconds sequentially on separate channels. Each channel corresponded to a different material/solution combination. Data files and summary statistics for the data collection period were saved automatically. A one minute delay separated sequential data files.

As shown in Figure 1, EN. evaluations require three electrodes: working electrode 1 (WE1), working electrode 2 (WE2) and a reference electrode. WE1 and WE2 are nominally the same material although in these experiments WE2 is stressed while WE1 was not. WE2 was common to both the measurement of ECN and EPN. Corrosion coupling current, or ECN, was measured between WE1 and WE2 through a zero resistance ammeter (ZRA). The sign convention of the ZRA was such that the ECN was negative when WE2 was anodic (corroding) with respect to WE1.

Electrochemical potential noise of WE2 was measured with respect to either a true reference, Fischer Scientific silver-silver chloride half cell directly immersed in the test solution, or against a pseudo-reference. Since voltage is measured on a relative scale, a reference electrode was used to provide a baseline against which to measure electrical potential (voltage). A pseudo-reference is a piece of the same material as WE2 which was immersed in the same solution. By using a pseudoreference, current and voltage signals (i.e. EN) could be evaluated against nominally identical electrodes. This provided greater sensitivity for potential changes due to localized corrosion events. On average, the corrosion potential of the pseudoreference was very close to that of WE2 and therefore acted as a "self-reference". Since WE2 and the pseudo-reference were connected only through a high resistance voltmeter, changes in potential experienced by WE2 were recorded with zero offset voltage (self reference).

In most cases the silver-silver chloride reference was used early in the testing so that movement of absolute potential could be recorded. By doing so, it was possible to compare the measured potential with electrochemical potentiodynamic polarization behavior measured prior to EN testing. This information was collected for academic more than practical interest since half cell electrodes are not stable in the environments of interest ${ }^{29}$. In most cases, the silver-silver chloride reference electrodes quickly deteriorated after only a few days of exposure and were removed. Pseudo-references were used to measure EPN after removal of the reference electrodes. The pseudo-references were used without difficulty for the remainder of the tests.

Approximately $25 \mathrm{~cm}^{2}$ of the U-bends for WE2 and $10 \mathrm{~cm}^{2}$ of the flat coupons used for WE1 and pseudo-references were submerged in the solution. Since it was difficult to determine the exposed area prior to the test, the electrochemical data were collected on the basis of the software default value of $1 \mathrm{~cm}^{2}$ of specimen area. Calculations of general corrosion rates subsequent to data collection were corrected for actual measured exposed area.

\section{Materials and Specimens}

Table 1 gives the test conditions and data file information. File names correspond to the last two digits of year (1994=94), alphabetical number of month (e.g. November $=\mathrm{K}$ ), date, alphabetical number of 24 hour time (e.g. $\mathrm{K}=11: 00$ ), and minutes. For example, file $94 \mathrm{~K} 10 \mathrm{~K} 33$ was started on November 10, 1994 at 11:33.

Testing was performed using simple pre-fabricated specimens. These samples illustrate that, in concept, sensors should be simple and robust. Flat coupons and $U$-bends of $A 516$ and A537 were used. The U-bend specimens were manufactured and stressed in accordance with ASTM G30. Stainless steel weld rod was spot welded to the specimens and was used to make the electrical connections to the electrochemical equipment. However, care was taken to not immerse the stainless steel in the test solution to eliminate possible galvanic effects.

Specimens were prepared to facilitate the initiation of localized corrosion phenomena. Specimen surfaces were not intended to represent actual waste tank wall conditions. U-bend specimens were prepared to facilitate the initiation of stress corrosion cracking by scoring a notch into the surface of the U-bend in the region of maximum stress. Flag electrodes were wet polished lightly with 600 grit sandpaper to facilitate the initiation of pitting corrosion. Specimens were degreased with acetone and cleaned with methanol and distilled water prior to submersion in the test solution.

(2) Registered Trademark of Capcis March Ltd. 
High rates of localized or general corrosion probably occur infrequently, if ever, in the waste tanks under "normal" or reference waste tank chemistry conditions. This assumption is supported by previous testing ${ }^{23}$ and over 400 tank-years of operation at Hanford under the current DST chemistry controls ${ }^{1}$. In the reference case, steel submerged in solutions will be passive and there will be very little corrosion activity and little, if any, electrochemical noise. Further, general corrosion, passivity, stress corrosion cracking and pitting all occur at different absolute electrochemical corrosion potentials (ECPs). Therefore, they do not occur at the same instant on the same material in the same solution. Although a deviation from actual service condition, in order to verify that EN could detect and discriminate between various forms of localized and general corrosion, it was necessary to induce the desired forms of corrosion by chemically shifting the ECP in to the range where each form of corrosion could occur.

The available literature and tank specifications were reviewed and individuals and organizations with experience in corrosion

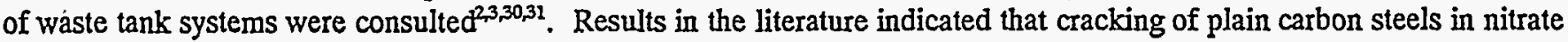
solutions was fairly straightforward ${ }^{2}$. However, private communication from more recent investigators indicate that this may not be true and that cracking results were somewhat variable with substantial heat to heat variations $\mathrm{s}^{32}$. It was decided that $5 \mathrm{M}$ and $11 \mathrm{M} \mathrm{NaNO}_{3}$ with $0.3 \mathrm{M}$ and $0.15 \mathrm{M} \mathrm{NaOH}$, respectively, at temperatures above $90^{\circ} \mathrm{C}$ would be reasonably close to possible off-normal tank operating conditions and produce some form of localized corrosion, either pitting, stress corrosion, or stress assisted intergranular attack on the mild steels of interest.

Solutions were prepared from reagent grade $\mathrm{NaNO}_{3}$ and $\mathrm{NaOH}$ with distilled, demineralized water. The error in molarity of the solutions is estimated to be $\pm 0.02 \mathrm{moles} / \mathrm{liter}(\mathrm{M})$. Temperature-controlled electrochemical vessels were used to maintain the test solutions within $\pm 2^{\circ} \mathrm{C}$ of the desired test temperature. Since the waste tank solutions are in contact with air, no attempt was made to deaerate the test solutions. The $\mathrm{pH}$ of the solution was periodically measured ensure that the $\mathrm{pH}$ was greater than 12 .

At termination of testing, the specimens were removed from solutions and metallographically examined to correlate EN data with corrosion damage.

\section{RESULTS AND DISCUSSION}

\section{Post-test Appearance of Specimens}

The specimens had a dull metallic finish where they had been submerged in the solution. The specimens were more heavily corroded above the solution level than below the solution level (Figure 2), similar to the reported appearance of the tanks themselves ${ }^{33}$. This effect was caused by moisture from the simulated waste solution evaporating at the liquid/air interface and condensing on the metal surfaces in the vapor space. This condensate contained little or no $\mathrm{NaOH}$ as compared to the solution and was saturated with oxygen. The net effect was uniform corrosion at and above the liquid/vapor interface and localized forms of corrosion below the liquid/vapor interface.

\section{Summary Statistical Data}

Tests were conducted for between 140 and 240 hours. In this time period, more than 1250 data files were collected requiring 16 megabytes of storage. Summary statistical information from each of the 1250 data files were gathered using the DENIS123 $3^{(3)}$ software. This software package interrogates each of the data files and collects mean, standard deviation and root mean square statistics for the ECN and EPN data sets along with resistance noise $\left(R_{n}\right)$ and degree of localization (DOL) for the data files. The DOL is the ratio of the standard deviation of the ZRA current for a particular set of EN data to the root mean square ZRA current and has been reported to be a simple and reliable measure of the tendency towards localized corrosion behavio ${ }^{19,21}$. The resistance noise is the ratio of the standard deviation of potential to the standard deviation of current for a particular set of data and can be related to charge transfer resistance. These summary statistics give an overview of the electrochemical progression of the material in the environment. Presentation of each of the 1250 EN data files is not feasible or practical. By reviewing the trends of the statistical parameters, periods of electrochemical activity can be identified

(3) Registered Trademark of Capcis March Ltd. 
and a detailed examination of the electrochemical noise records for the period made. Complete data sets are available from . the authors. The following is a summary of corrosion behavior observed for each of the material/environment combinations investigated:

$\mathrm{A} 516$ in $5 \mathrm{M} \mathrm{NaNO}_{3}+0.30 \mathrm{M} \mathrm{NaOH} @ 90^{\circ} \mathrm{C}$ for $220 \mathrm{~h}$

Figures 3 through 8 show the mean and standard deviation of ECN, mean and standard deviation of EPN, $R_{\mathfrak{n}}$, and DOL for A516 in $5 \mathrm{M} \mathrm{NaNO}_{3}+0.30 \mathrm{M} \mathrm{NaOH}$.

After the specimen was initially immersed in the test solution, the EN data were dominated by the establishment of equilibrium between the clean metal and oxygenated test solution. The mean corrosion current was net cathodic (positive) for WE2 (U-bend) during the first several scans as the fresh metal surfaces promote cathodic reactions which registered as positive currents through the ZRA (Figure 3). Mean corrosion current decreased over the next five hours, passing through zero and eventually becoming negative (anodic). The standard deviation of the ZRA current (Figure 4) increased with the increased anodic activity on WE2.

The potential of the specimen increased (became more noble) from $-340 \mathrm{mV}$ to $-175 \mathrm{mV}$ versus $\mathrm{Ag} / \mathrm{AgCl}$ (Figure 5) during the first 86 hours. The standard deviation of EPN increased (Figure 6) along with the standard deviation of the ZRA current and was indicative of pit initiation. Pitting transients generally occurred when the mean specimen potential was between -230 and $-240 \mathrm{mV}$ versus $\mathrm{Ag} / \mathrm{AgCl}$. The value of $\mathrm{R}_{\mathrm{n}}$ varied between 1,000 and 10,000 ohms (Figure 7).

After approximately 86 hours of exposure, the specimens were removed and examined. After examination, the specimens were placed back in the solution and the true reference was replaced by a flat specimen of A516 from the same heat of material which served as pseudo-reference for the remainder of the experiment. Note that the potential of WE2 was approximately $100 \mathrm{mV}$ more positive (anodic) in potential with respect to the pseudo-reference (unstressed material). The effect of removal and restart of the experiment can be seen in Figures 3 and 5.

The DOL increased and decreased over the course of the testing as pitting initiated and propagated (Figure 8). Detailed analysis of the time records for this test showed that pit propagation transients appeared after about 36 hours into the test.

Figure 9 shows the detailed ECN and EPN records for a large series of pitting and "reverse" pitting events approximately 96 hours into the test. Current transients were on the order of 5 to $6 \mu \mathrm{A}$ and WE2 was anodic with respect to WE1. Occasionally during the course of the testing "reverse" pitting transients were observed (e.g. at 250 and 275 seconds of Figure 9) which correspond to pitting of WE1, the flat coupon connected to WE2 through the ZRA. Pitting damage was confirmed by post test metallographic examination. Examination of the surfaces of the $U$-bends and the flat specimens showed extensive pitting (Figures 10(a) and 10(b)). Pit density varied significantly over the surface. Pit densities were highest near the -solution/air interface due probably to the greater availability of oxygen at this location (Figure 10(a)).

No evidence of stress corrosion cracking was observed on the U-bend or other specimens. High magnification examination of the entire surface of the specimen was not possible but pitting was obviously the dominant corrosion damage mechanism for A516 in this environment from both the EN and metallographic analyses.

$\mathrm{A} 516$ in $11 \mathrm{M} \mathrm{NaNO}_{3}+0.15 \mathrm{M} \mathrm{NaOH} @ 95^{\circ} \mathrm{C}$ for $100 \mathrm{~h}$

Figures 11 through 16 show the mean and standard deviation of ECN, mean and standard deviation of EPN, $R_{n}$, and DOL for $\mathrm{A} 516$ in $11 \mathrm{M} \mathrm{NaNO}+0.15 \mathrm{M} \mathrm{NaOH}$.

For the first 48 hours after immersion, the mean current vacillates between positive (cathodic) and negative (anodic) values (Figure 11). Standard deviations of current and potential were largest between 24 and 48 hours after immersion (Figures 12 and 14). After approximately 48 hours, mean potentials of the stressed specimen versus the pseudo-reference were slightly negative (cathodic). The value of $R_{n}$ was stable (Figure 15), but DOL increased to near unity after 48 hours.

Detailed investigation of the EN data exhibited large current and potential transients superimposed on a background of transients in both the positive and negative directions.(Figures 17 and 18). More current transients were positive than negative in direction which accounts for the more cathodic potential of the stressed electrode versus the unstressed pseudo-reference electrode. Current transients in the positive direction with net cathodic mean currents are indicative of stress corrosion cracking. Current transients in the negative direction are generally associated with pitting events. 
Data in Figure 17 shows a positive mean current that remains positive when large current and voltage transients begin to occur. The transients at 80 seconds are indicative of stress corrosion cracking while the transients at 320 seconds are indicative of a pitting event. The mean current remained positive and more stress corrosion cracking transients were recorded (Figures 11 and 18).

At low magnification, the surface appeared relatively unaffected by 100 hours of exposure (Figure 19(a)). At higher magnifications, the surface of the specimen revealed macropits, micropits and cracks (Figure 19(b)).

Stress corrosion cracking of mild steels in nitrate solutions has been reported to be intergranular and the result of active path dissolution mechanism ${ }^{30,31}$. The presence of pits and stress corrosion cracks on the same specimen was confirmed by EN signals and metallographic examination. Pitting is generally associated with the transpassive behavior of a material. Active path stress corrosion cracking can be associated with the passive to active transition behavior of the material. The EN data suggests that the material oscillated between these two types of corrosion phenomena. This result further suggests that the increased concentration of nitrate in the solution may narrow the potential range over which the material is passive in the environment. This would mean that relatively small shifts in potential would result in shifting from pitting to stress corrosion cracking and visa versa. It is not possible from these tests to determine if this is the case. Nonetheless, EN analysis detected and predicted both stress corrosion cracking and pitting and both forms of corrosion damage were confirmed by metallography.

Further investigation would be necessary to determine why both types of localized corrosion occurred in this environment. One possibility is that the localized corrosion mechanism is stress assisted intergranular attack as has been reported by others ${ }^{19}$. The metallographically observable corrosion damage resulting from stress assisted intergranular attack is similar to intergranular stress corrosion cracking. Since the duration of this experiment was only 100 hours, it is possible that the electrochemical signals and the comosion damage observed represent the initiation of stress assisted intergranular attack.

A537 in $5 \mathrm{M} \mathrm{NaNO}_{3}+0.3 \mathrm{M} \mathrm{NaOH} @ 95^{\circ} \mathrm{C}$ for $242 \mathrm{~h}$

Figures 20 through 25 show the mean and standard deviation of ECN, mean and standard deviation of EPN, $R_{n}$, and DOL for $\mathrm{A} 537$ in $5 \mathrm{M} \mathrm{NaNO}_{3}+0.3 \mathrm{M} \mathrm{NaOH}$.

After the specimen was initially immersed in the test solution, the mean corrosion current was net anodic (negative) for WE2 (U-bend) during the first 24 to 36 hours (Figure 20). Mean corrosion current increased over time, passed through zero and became positive during the first 80 hours. The standard deviation of the ZRA current (Figure 21) was large over the first 36 hours, as compared to the period between 36 and 80 hours.

The potential of the specimen increased (became more noble) from $-340 \mathrm{mV}$ to $-225 \mathrm{mV}$ versus $\mathrm{Ag} / \mathrm{AgCl}$ (Figure 22) during the first 86 hours. The standard deviation of EPN increased (Figure 23) along with the standard deviation of the ZRA current and was indicative of pit initiation. The value of $R_{\mathrm{n}}$ varied between 1,000 and 10,000 ohms (Figure 24).

After approximately 80 hours of exposure, the specimens were removed and examined. After examination, the specimens were placed back in the solution and the true reference was replaced by a flat specimen of A537 from the same heat of material which served as pseudo-reference for the remainder of the experiment. Note that the potential of the U-bend specimen was approximately $50 \mathrm{mV}$ more negative (cathodic) in potential with respect to the pseudo-reference (unstressed material). The disruptive effect of removal and restart of the experiment can be seen in Figures 20 and 22 .

The DOL increased and decreased over the course of the testing as pitting initiated and propagated (Figure 25). Figure 26 shows the detailed ECN and EPN records for pitting events approximately 30 hours into the test. Current transients were on the order of 10 to $30 \mu \mathrm{A}$ and WE2 was anodic with respect to WE1. The number of pitting transients observed over the course of the test with $\mathrm{A} 537$ in $5 \mathrm{M} \mathrm{NaNO}_{3}+0.3 \mathrm{M} \mathrm{NaOH} @ 95^{\circ} \mathrm{C}$ were small in number as compared to $\mathrm{A} 516$ in the same environment, as can be seen by comparing Figure 26 with Figure 9.

Pitting damage was confirmed by post test metallographic examination of the surfaces of the U-bends and the flat specimens (Figures 27(a) and 27(b)). The size and density of the pits were less than was observed on the A516 material in a similar solution (Figures 27(a), 27(b), 10(a) and 10(b)). 
No evidence of stress corrosion cracking was observed on the U-bend or other specimens. Examination of the entire surface of the specimen was not possible and pitting was the dominant corrosion damage mechanism from both the EN and metallographic analyses.

The behavior of $\mathrm{A} 537$ material in $5 \mathrm{M} \mathrm{NaNO}_{3}+0.3 \mathrm{M} \mathrm{NaOH} @ 95 \mathrm{C}$ was similar to that of $\mathrm{A} 516$ in the same environment. Pitting was the dominant in behavior but fewer pitting transients were observed, on average, when compared with the A516. The differences in electrochemical behavior is likely related to compositional and microstructural differences in the materials.

\section{GENERAL CORROSION RATES AS DETERMINED BY EN AND LPR}

During the course of the tests, linear polarization (LPR) tests were occasionally performed to measure general corrosion rates on the specimens. General corrosion rates can also be predicted from the average $R_{n}$ values collected during the EN scans. The purpose of these tests was to compare the general corrosion rates recorded by the two techniques.

General corrosion rates measured using LPR data were typically on the order of 0.25 mils per year (mpy) for all three alloys in $5 \mathrm{M} \mathrm{NaNO}_{3}+0.3 \mathrm{M} \mathrm{NaOH} @ 90^{\circ} \mathrm{C}$. General corrosion rates for A516 and A537 calculated from average $R_{\mathrm{u}}$ data were between 0.2 and $0.4 \mathrm{mpy}$ in $5 \mathrm{M} \mathrm{NaNO}+0.3 \mathrm{M} \mathrm{NaOH} @ 90^{\circ} \mathrm{C}$. General corrosion rate for mild steels calculated in the Hanford Unified Waste Model from chemistry of the simulated solutions are -0.4 mpy. This model is a based on work performed at Pacific Northwest Laboratory between 1980 and 1985. Over 3000 data points from 60 different waste chemistries were collected and analyzed to produce this model ${ }^{3,36}$.

\section{SUMMARY AND CONCLUSIONS}

Proof of principle tests using electrochemical noise analysis were conducted with A516 and A537 mild steels in concentrated $\mathrm{NaNO}_{3} / \mathrm{NaOH}$ solution at temperatures above $90^{\circ} \mathrm{C}$. The purpose was to verify the capability of EN evaluation to detect localized corrosion. Tests were conducted for between 140 and 240 hours. Electrochemical noise signals were correlated with post-test metallographic examination of specimen surfaces. The following conclusions are supported by the test results:

1. EN was shown to be capable of detecting and discriminating between uniform and localized corrosion events.

2. EN detected pitting on $\mathrm{A} 516$ and $\mathrm{A} 537$ in $5 \mathrm{M} \mathrm{NaNO}_{3}+0.3 \mathrm{M} \mathrm{NaOH}$ solutions. Pitting damage was confirmed by metallographic examination. Pitting on A516 was more extensive as compare to A537.

3. EN detected and discriminated between cracking and pitting phenomena on 516 in $11 \mathrm{M} \mathrm{NaNO}_{3}+0.15 \mathrm{M} \mathrm{NaOH}$ solutions. Appearance of both indicates that passive region of $11 \mathrm{MNaNO}_{3}+0.15 \mathrm{M} \mathrm{NaOH}$ may have been narrower, as compared with $\mathrm{A} 516$ in the $5 \mathrm{M} \mathrm{NaNO}_{3}+0.3 \mathrm{M} \mathrm{NaOH}$ environment. With a narrower passive region, localized corrosion could shift between the two localized corrosion phenomenon. Another possibility is that the localized corrosion mechanism is stress assisted intergranular attack as has been reported by others ${ }^{19}$. The metallographically observable corrosion damage resulting from stress assisted intergranular attack is similar to intergranular stress corrosion cracking.

4. Considering the short testing period, other forms of corrosion which have been reported in the literature (stress assisted intergranular attack) may have needed longer time for conditions to develop. This was particularly true of the $11 \mathrm{M} \mathrm{NaNO}_{3}+0.15 \mathrm{M} \mathrm{NaOH}$ solution.

5. There is good agreement between general corrosion rates predicted by LPR and $R_{n}$ data, Hanford models and literature reported rates.

6. Results from these tests provide sufficient proof of principle of the EN technology to proceed with in-tank development of an operational prototype system. 


\section{ACKNOWLEDGMENTS}

The work presented here represents the true cooperative efforts of many people and organizations from diverse backgrounds and ranges of interest. The tests were conducted at Oak Ridge National Laboratory in the Corrosion Science and Technology Group of the Metals and Ceramics Division. Mr. Jim DiStefano is the Group Leader of the Corrosion Science and Technology Group. The technical support of Dr. Kevin Lawson and Dr. Bill Cox of CML, Inc. is gratefully acknowledged. The work would not have been possible without the administrative efforts of Mr. Dave Roarty of Westinghouse Electric Company and Mr. Jim Nelson and Dr. Bill Brehm of Westinghouse Hanford Company. 


\section{REFERENCES}

1. P.C. Ohl, J.D. Thomson, and F.R. Vollert, "Corrosion Considerations for Life Management of Hanford High Level Waste Tanks," CORROSION/94, paper no. 142, (Houston, TX: NACE International, 1994).

2. D.C. Lini, "Compilation of Hanford Corrosion Studies," Atlantic Richfield Hanford Company Report, ARH-ST-111, UC-70, July 1975

3. J.R. Divine, et al., "Prediction Equations for Corrosion Rates of A-537 and A-516 Steels in Double Shell Slurry, . Future PUREX, and Hanford Facilities Wastes," Pacific Northwest Laboratory Report, PNL-5488, June 1985.

4. W.C. Carlos et al., "Recommendations for.Erosion/Corrosion Allowance for Multi-Function Waste Tank Facility Tanks," CORROSION/95, paper no. 449, (Houston, TX: NACE International, 1995).

5. J. Nelson et al., "Hanford DST Corrosion Monitoring Instrument Tree," CORROSION/95, paper no. 440, (Houston, TX: NACE International, 1995).

6. R.K. Shukla, et al., "Corrosion Monitoring of High Level Waste Storage Tank 8-D2 at the West Valley Demonstration Project," CORROSION/94, paper no. 121, (Houston, TX: NACE International, 1994).

7. J.I. Mickalonis, "The Use of Electrochemical Noise Measurements with Nuclear Waste Tanks," First International Symposium on Electrochemical Noise for Corrosion Applications - Montreal, Canada, May 16-17, 1994, (Philadelphia, PA: ASTM, 1994).

8. T. Haygard and J. R. Williams, Trans. Farad. Soc. 57, (1961): p. 2288-2298.

9. P. Bindra, et al., Discussions of Faraday Soc. 56, (1974): p. 189-209.

10. M. Fleischmann, et al., Surface Science 100-101, (1980): p. 583-601.

11. G. J. Bignold and M. Fleischmann, Electrochemical Acta 19, (1974): p. 363-374.

12. E. Budevski, et al., Electrochemical Acta 28, (1983): p. 925-931.

13. G. Blanc, et al., Electrochemical Acta 23, (1978): p. 337-340.

14. K. Hladky and J. L. Dawson, Corrosion Science 22, (1982): p. 231-237.

15. D. A. Eden, et al., International Patent Classification G01N17/00, 19 Nov 87.

.16. $\quad$ K. Hladky, U.S. Patent No. 4,575,678, March 11, 1986.

17. U. Bertocci, "Electrochemical Noise Analysis and Its Application to Corrosion," CORROSION/89, paper no. 24, (Houston, TX: NACE International, 1989).

18. J. L. Dawson, et al., "Corrosion Monitoring Using Electrochemical Noise Measurements," CORROSION/89, paper no. 31, (Houston, TX: NACE International, 1989).

19. D. A. Eden, A. N. Rothwell, and J. L. Dawson, "Electrochemical Noise for Detection of Susceptibility to Stress Corrosion Cracking," CORROSION/91, paper no. 444, (Houston, TX: NACE International, 1991).

20. D. M. Farrell, Industrial Corrosion 9, (1991): p. 7-13.

21. A. N. Rothwell, T. G. Walsh and W. M. Cox, "On Line Corrosion Investigation and Surveillance - Chemical Plant Case Studies," CORROSION/91, paper no. 170, (Houston, TX: NACE International, 1991).

22. J. L. Dawson, et al., On-line Monitoring of Continuous Process Plants, D. Butcher, editor (Ellis Horwood, 1983). 
23. D. M. Farrell, W. M. Cox, and D. Gearey, Multi-System Corrosion Monitoring in a Cyclic Reheat Test Facility; Phase 1, EPRI CS-5776 (Pleasant Hill, CA: Electric Power Research Institute, 1988).

24. D. M. Farrell, W. M. Cox, and D. Gearey, Multi-System Corrosion Monitoring in FGD Systems; Phase 2, EPRI CS5734 (Pleasant Hill, CA: Electric Power Research Institute, 1988).

25. W. M. Cox and B. C. Syrett, "The Future of On-line Materials Surveillance for Operating Process Plants," Life Prediction of Corrodible Structures - Cambridge, UK, Sept., 1991, (Houston, TX: NACE Intemational, 1991).

26. W. M. Cox and H. D. Spriggs, "On-line Surveillance Instrumentation for Failure Investigation, Materials Evaluation and Process Control in Combustion Equipment," Fifth Annual International Pittsburgh Coal Conference - Pittsburgh, PA, Sept., 1988, (Pittsburgh, PA, 1988).

27. P.E. Doherty, et al., "An Application of Advanced Electrochemical Monitoring of Corrosion of Heat Exchanger Tubing," Fourth International Symposium on Environmental Degradation of Materials in Nuclear Power Systems Jekyll Island, GA, Aug., 1989, (Houston, TX: NACE International, 1989).

28. D.A. Eden and J.L. Dawson, "Transformation of Electrochemical Noise Data into Impedance Spectra," First International Symposium on Electrochemical Noise for Corrosion Applications - Montreal, Canada, May 16-17, 1994, (Philadelphia, PA: ASTM, 1994).

29. M. J. Danielson, "The Effect of Gamma Radiation on Reference Electrodes and Platinum and Carbon Steel Bare Metal Electrodes in Simulated Waste Solution," CORROSION/94, paper no. 149, (Houston, TX: NACE International, 1994).

30. J. A. Donovan, "Factors Controlling Nitrate Cracking of Mild Steels," Environmental Degradation of Engineering Materials - Blacksburg, VA, Oct. 10-12, 1977, (Blacksburg, VA: Virginia Tech Printing Department, 1977).

31. S.W. Ciaraldi, Stress Corrosion Cracking of Carbon and Low Alloy Steels (Yield Strengths less than 1241 Mpa), (Metals Park, OH: American Society of Metals, 1979), p.17.

32. M.J. Danielson, Private Communication with G.L. Edgemon, November 1994.

33. P.C. Ohl, "Internal Corrosion of Buried Waste Storage Tanks at Hanford," NACE International Western Region Corrosion Conference and Education Week - Seattle, WA, Oct. 31-Nov. 4, 1994, (Houston, TX: NACE. International, 1994).

34. J.R. Divine, W.M. Bowen, D.B. Mackey, D.J. Bates, and K.H. Pool, "Prediction Equations for Corrosion Rates of A-537 and A-516 Steels in Double Shell Slurry, Future PUREX, and Hanford Facilities Waste," Westinghouse Hanford Company, WCH-SD-WM-TI-467, January 1985. 
TABLE 1

TEST MATERIALS, CONDITIONS, AND DATA FILE INFORMATION

\begin{tabular}{|c|c|c|c|c|c|c|c|}
\hline $\begin{array}{l}\text { UNS\#, } \\
\text { ASTM\#, } \\
\text { Heat ID }\end{array}$ & $\begin{array}{c}\text { Solution } \\
\text { Chemistry }\end{array}$ & $\begin{array}{c}\text { Temp. } \\
\left({ }^{\circ} \mathrm{C}\right)\end{array}$ & $\mathrm{pH}$ & Data Files & First Data & Last Data & $\begin{array}{l}\text { Approx. } \\
\text { Immersion } \\
\text { Time (h) }\end{array}$ \\
\hline $\begin{array}{c}\text { K02100 } \\
\text { A516 } \\
\text { HT-F215 }\end{array}$ & $\begin{array}{l}5 \mathrm{M} \mathrm{NaNO}_{3}+ \\
0.30 \mathrm{M} \mathrm{NaOH}\end{array}$ & 90 & $12+$ & $\begin{array}{c}94 \mathrm{~K} 10 \mathrm{~K} 33 \\
\text { to } \\
94 \mathrm{~K} 20058\end{array}$ & $\begin{array}{c}11 / 10 / 94 \\
@ \\
13: 58\end{array}$ & $\begin{array}{c}\text { 11/20/94 } \\
@ \\
13: 58\end{array}$ & 220 \\
\hline $\begin{array}{c}\mathrm{K} 02100 \\
\text { A516 } \\
\text { HT-F215 }\end{array}$ & $\begin{array}{c}11 \mathrm{M} \mathrm{NaNO}_{3} \\
+0.15 \mathrm{M} \\
\mathrm{NaOH}\end{array}$ & 95 & $12+$ & $\begin{array}{c}94 \mathrm{~K} 16 \mathrm{~J} 25 \\
\text { to } \\
94 \mathrm{~K} 20 \mathrm{P} 08\end{array}$ & $\begin{array}{c}11 / 16 / 94 \\
@ \\
10: 25\end{array}$ & $\begin{array}{c}11 / 20 / 94 \\
@ \\
12: 08\end{array}$ & 100 \\
\hline $\begin{array}{c}\mathrm{K} 02400 \\
\mathrm{~A} 537 \\
\mathrm{HT}-\mathrm{J} 415\end{array}$ & $\begin{array}{l}5 \mathrm{M} \mathrm{NaNO}_{3}+ \\
0.30 \mathrm{M} \mathrm{NaOH}\end{array}$ & 95 & $12+$ & $\begin{array}{c}94 \mathrm{~K} 10 \mathrm{P} 09 \\
\text { to } \\
94 \mathrm{~K} 20 \mathrm{P} 17\end{array}$ & $\begin{array}{c}11 / 10 / 94 \\
@ \\
12: 09\end{array}$ & $\begin{array}{c}11 / 20 / 94 \\
@ \\
12: 17\end{array}$ & 216 \\
\hline
\end{tabular}




\section{LIST OF CAPTIONS}

Figure 1: $\quad$ Test cell and electrode configuration

Figure 2: $\quad$ Post test appearance of $U$-bend and flat coupon specimens exposed to simulated defense nuclear waste.

Figure 3: $\quad$ Mean ZRA current versus immersion time for $\mathrm{A} 516$ in $5 \mathrm{M}$ nitrate $+0.15 \mathrm{M}$ hydroxide solution for 220 hours.

Figure 4: Standard deviation of ZRA current versus immersion time for $\mathrm{A} 516$ in $5 \mathrm{M}$ nitrate $+0.15 \mathrm{M}$ hydroxide solution for 220 hours.

Figure 5: $\quad$ Mean potential with respect to reference versus immersion time for $\mathrm{A} 516$ in $5 \mathrm{M}$ nitrate $+0.15 \mathrm{M}$ hydroxide solution for 220 hours.

Figure 6: Standard deviation of EPN versus immersion time for A516 in 5M nitrate $+0.15 \mathrm{M}$ hydroxide solution for 220 hours.

Figure 7: $\quad$ Resistance noise versus immersion time for $\mathrm{A} 516$ in $5 \mathrm{M}$ nitrate $+0.15 \mathrm{M}$ hydroxide solution for 220 hours.

Figure 8: Degree of localization versus immersion time for $\mathrm{A} 516$ in $5 \mathrm{M}$ nitrate $+0.15 \mathrm{M}$ hydroxide solution for 220 hours.

Figure 9: $\quad$ Detailed EPN and ECN data for A516 in $5 \mathrm{M}$ nitrate $+0.15 \mathrm{M}$ hydroxide solution after approximately 95 hours of immersion.

Figure 10(a): $\quad$ Surface of A516 U-bend exposed to 5M nitrate $+0.15 \mathrm{M}$ hydroxide for 220 hours of immersion. Surface near solution/air interface (at top) shows higher pit density than surface below interface.

Figure 10(b): Surface of A516 U-bend exposed to $5 \mathrm{M}$ nitrate $+0.15 \mathrm{M}$ hydroxide for 220 hours of immersion. Close-up of pitting near solution interface.

Figure 11: $\quad$ Mean ZRA current versus immersion time for A516 in 11M nitrate + 0.30M hydroxide solution for 100 hours. 
Figure 12: Standard deviation of ZRA current versus immersion time for A516 in $11 \mathrm{M}$ nitrate $+0.30 \mathrm{M}$ hydroxide solution for 100 hours.

Figure 13: Mean potential with respect to reference versus immersion time for A516 in $11 \mathrm{M}$ nitrate $+0.30 \mathrm{M}$ hydroxide solution for 100 hours.

Figure 14: Standard deviation of EPN versus immersion time for A516 in $11 \mathrm{M}$ nitrate $+0.30 \mathrm{M}$ hydroxide solution for 100 hours.

Figure 15: Resistance noise versus immersion time for $\mathrm{A} 516$ in $11 \mathrm{M}$ nitrate $+0.30 \mathrm{M}$ hydroxide solution for 100 hours.

Figure 16: Degree of localization versus immersion time for $\mathrm{A} 516$ in $11 \mathrm{M}$ nitrate + $0.30 \mathrm{M}$ hydroxide solution for 100 hours.

Figure 17: $\quad$ Detailed EPN and ECN data for A516 in $11 \mathrm{M}$ nitrate $+0.30 \mathrm{M}$ hydroxide solution after approximately 41 hours of immersion.

Figure 18: Detailed EPN and ECN data for A516 in $11 \mathrm{M}$ nitrate $+0.30 \mathrm{M}$ hydroxide solution after approximately 58 hours of immersion.

Figure 19(a): Low magnification SEM micrograph of region near maximum stress on A516 $\mathrm{U}$-bend in $11 \mathrm{M}$ nitrate $+0.30 \mathrm{M}$ hydroxide solution after 100 hours of immersion.

Figure 19(b): Higher magnification SEM micrograph of micro cracking and pitting near region of maximum stress on $A 516 \mathrm{U}$ bend in $11 \mathrm{M}$ nitrate $+0.30 \mathrm{M}$ hydroxide solution after 100 hours of immersion.

Figure 20: Mean ZRA current versus immersion time for $A 537$ in $5 \mathrm{M}$ nitrate $+0.15 \mathrm{M}$ hydroxide solution for 216 hours.

Figure 21: Standard deviation of ZRA current versus immersion time for $\mathrm{A} 537$ in $5 \mathrm{M}$ nitrate $+0.15 \mathrm{M}$ hydroxide solution for 216 hours. 
Figure 22: $\quad$ Mean potential with respect to reference versus immersion time for A537 in 5M nitrate $+0.15 \mathrm{M}$ hydroxide solution for 216 hours.

Figure 23: Standard deviation of EPN versus immersion time for $\mathrm{A} 537$ in $5 \mathrm{M}$ nitrate $+0.15 \mathrm{M}$ hydroxide solution for 216 hours.

Figure 24: $\quad$ Resistance noise versus immersion time for $\mathrm{A} 537$ in $5 \mathrm{M}$ nitrate $+0.15 \mathrm{M}$ hydroxide solution for 216 hours.

Figure 25: Degree of localization versus immersion time for $\mathrm{A} 537$ in $5 \mathrm{M}$ nitrate $+0.15 \mathrm{M}$ hydroxide solution for 216 hours.

Figure 26: Detailed EPN and ECN data for A537 in $5 \mathrm{M}$ nitrate $+0.15 \mathrm{M}$ hydroxide solution after approximately 30 hours of immersion.

Figure 27(a): Optical micrograph of solution/air interface on surface of A537 U-bend in $5 \mathrm{M}$ nitrate $+0.15 \mathrm{M}$ hydroxide solution after 216 hours of immersion.

Figure 27(b): Higher magnification optical micrograph of pitting near solution/air interface on surface of A537 U-bend in $5 \mathrm{M}$ nitrate $+0.15 \mathrm{M}$ hydroxide solution after 216 hours of immersion. 


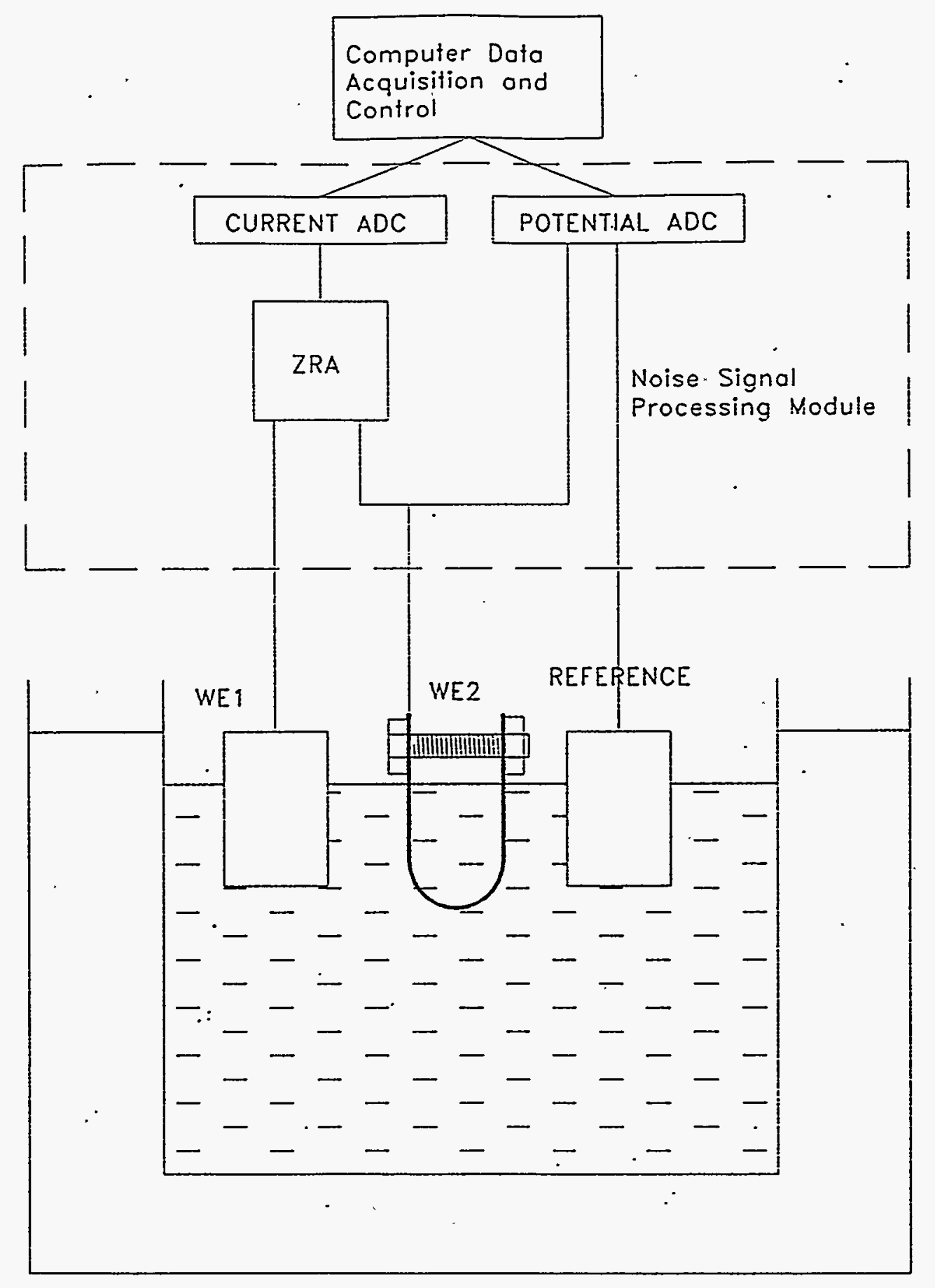

Figure 1: Test Cell and Electrode Configuration. 

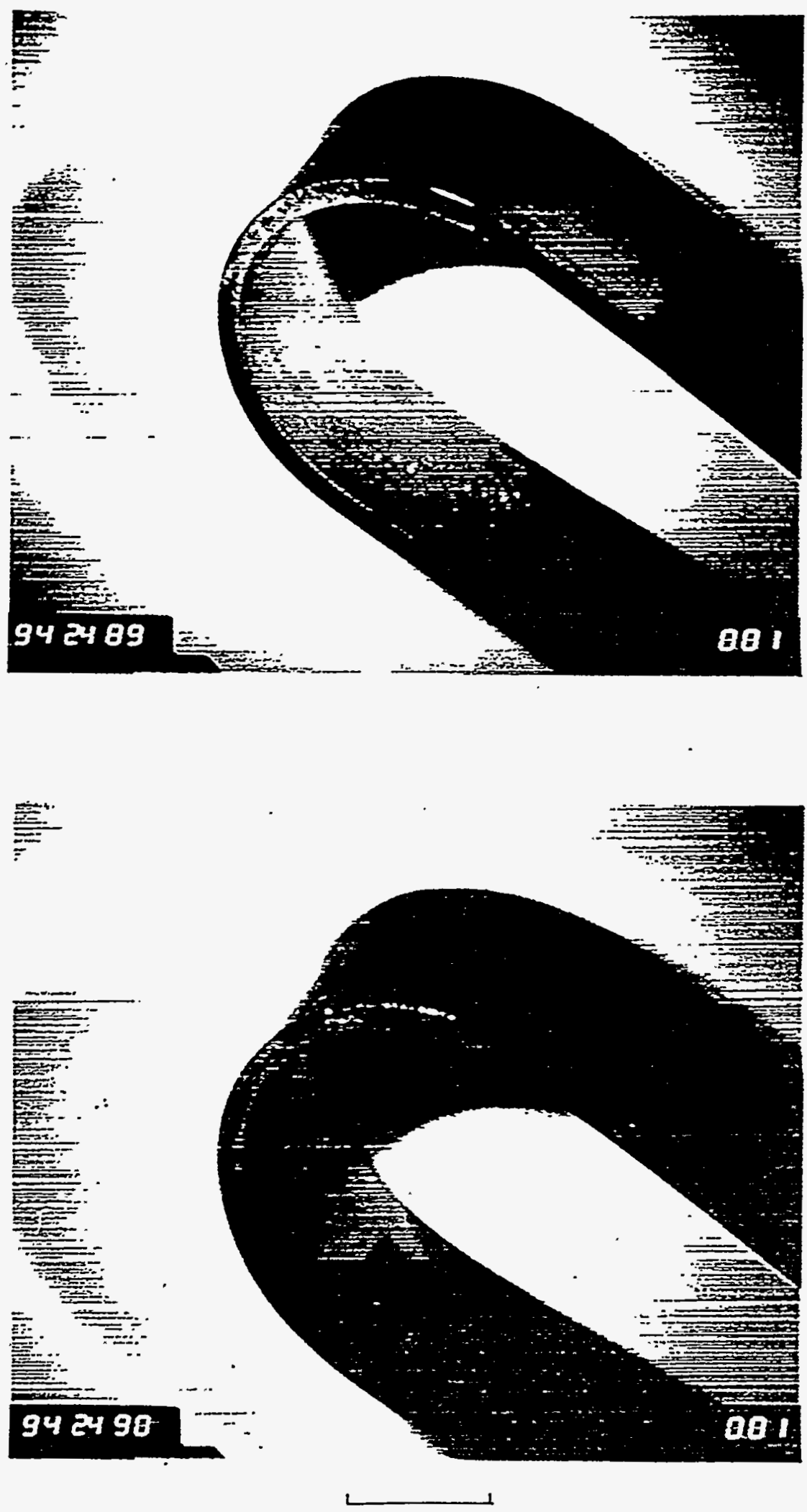

Figure 2: $\quad$ Post test appearance of U-bend and flat coupon specimens exposed to simulated defense nuclear waste. 


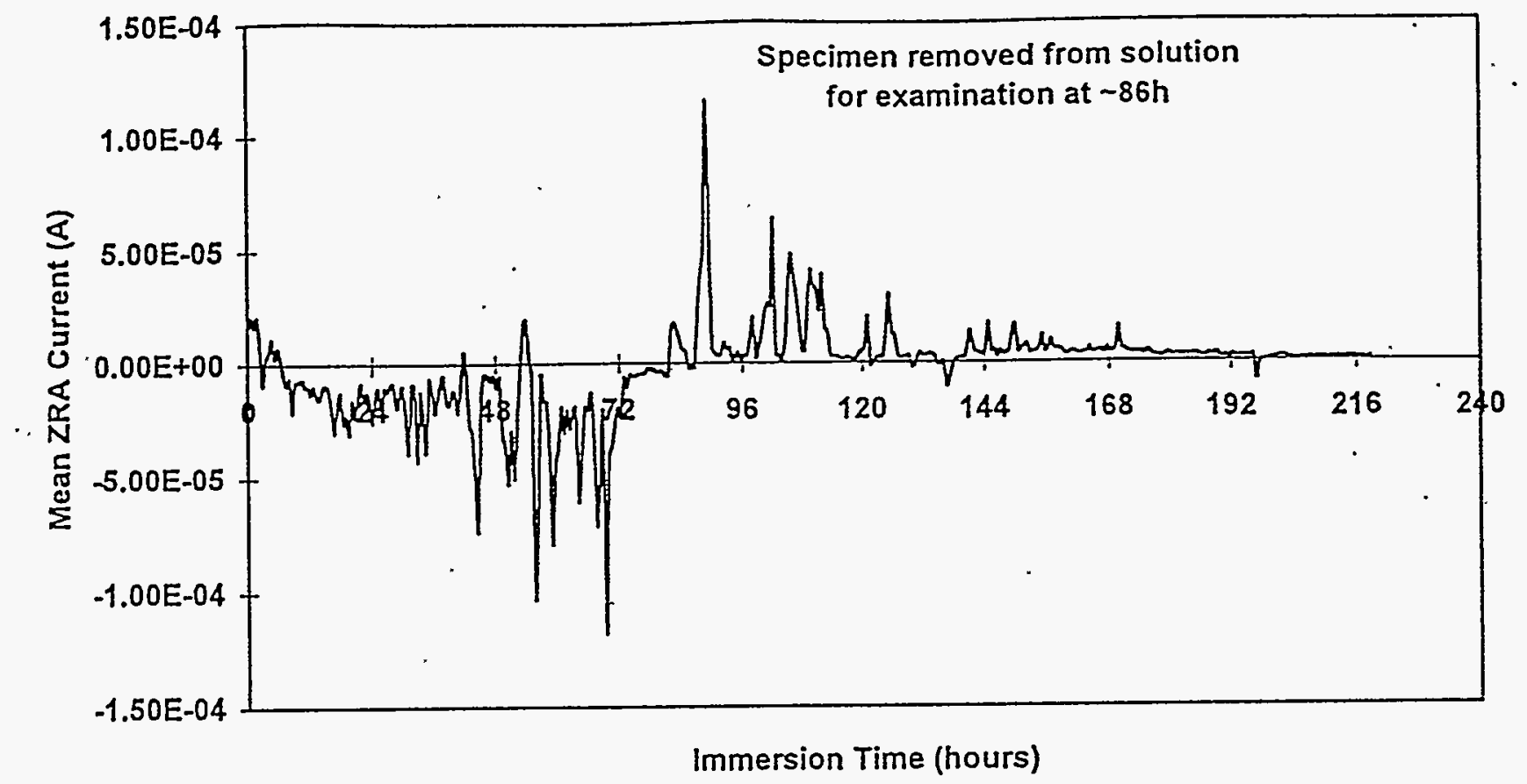

Figure 3: $\quad$ Mean ZRA current versus immersion time for $A 516$ in $5 \mathrm{M}$ nitrate $+0: 15 \mathrm{M}$ hydroxide solution for 220 hours.

\section{Standard Deviation of Mean Current Noise - A51603}

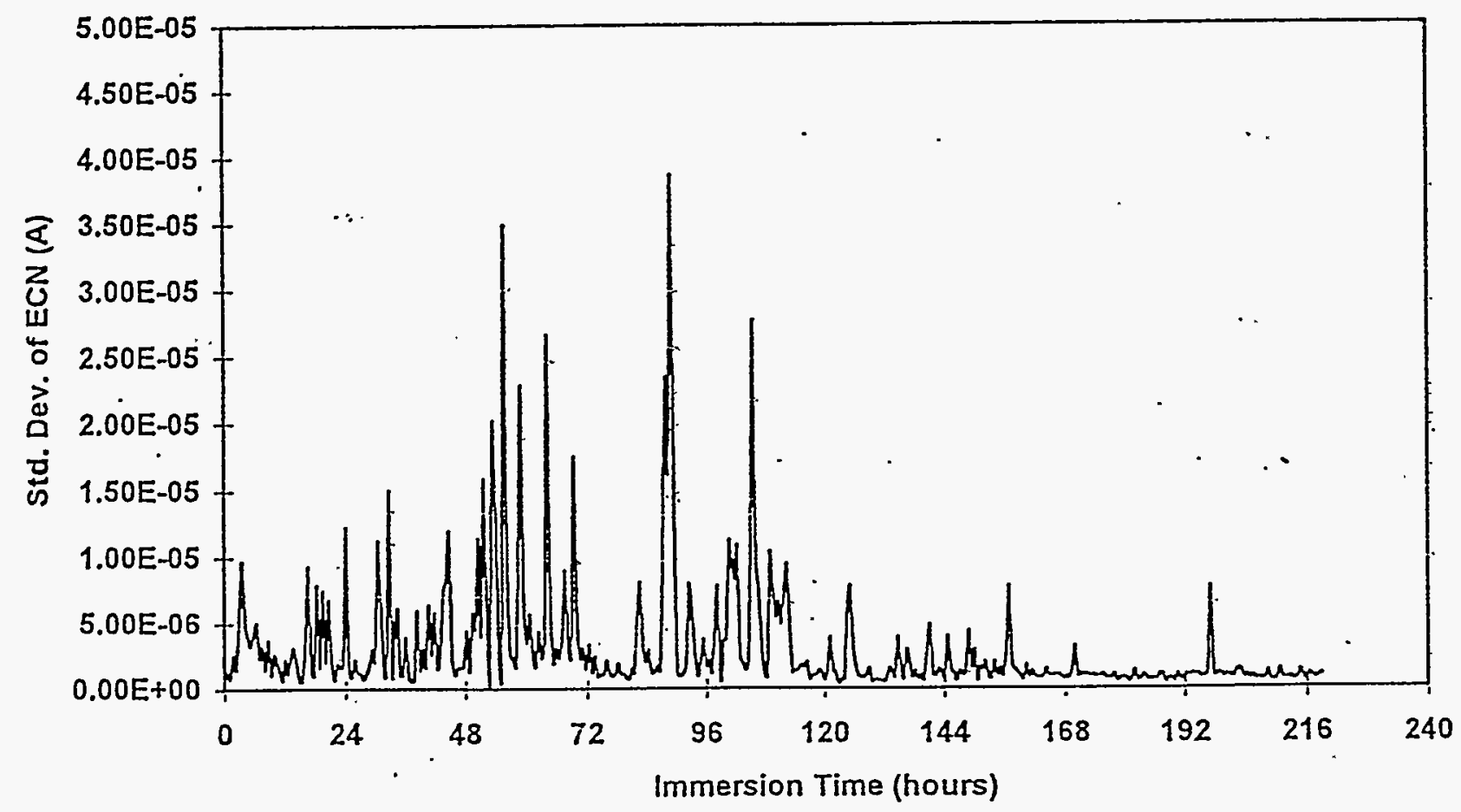

Figure 4: $\quad$ Standard Deviation of ZRA current versus immersion time for A516 in 5M nitrate + $0.15 \mathrm{M}$ hydroxide solution for 220 hours. 


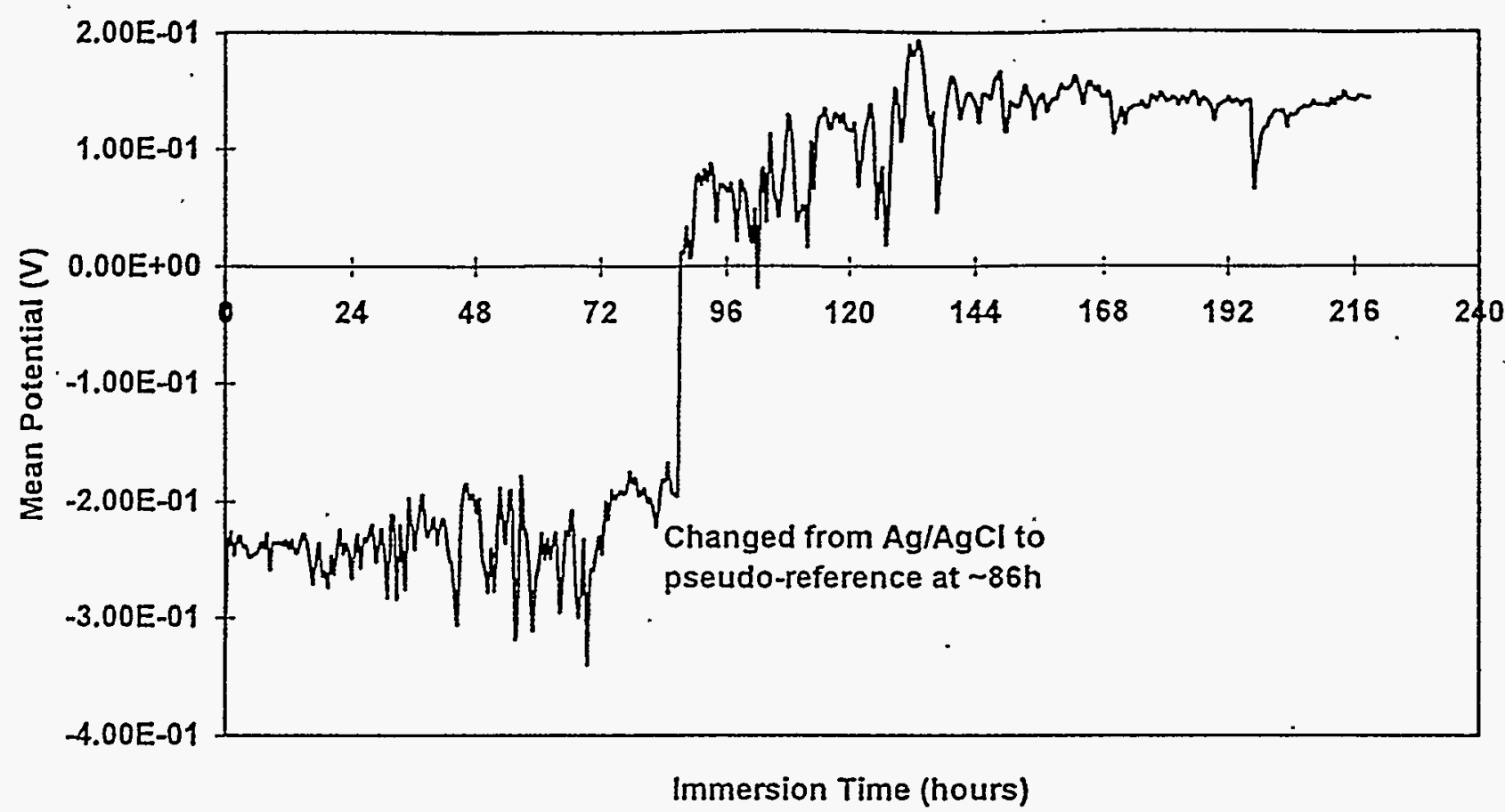

Figure 5: Mean potential with respect to reference versus immersion time for $\mathrm{A} 516$ in $5 \mathrm{M}$ nitrate $+0.15 \mathrm{M}$ hydroxide solution for 220 hours.

\section{Standard Deviation of Potential Noise - A51603}

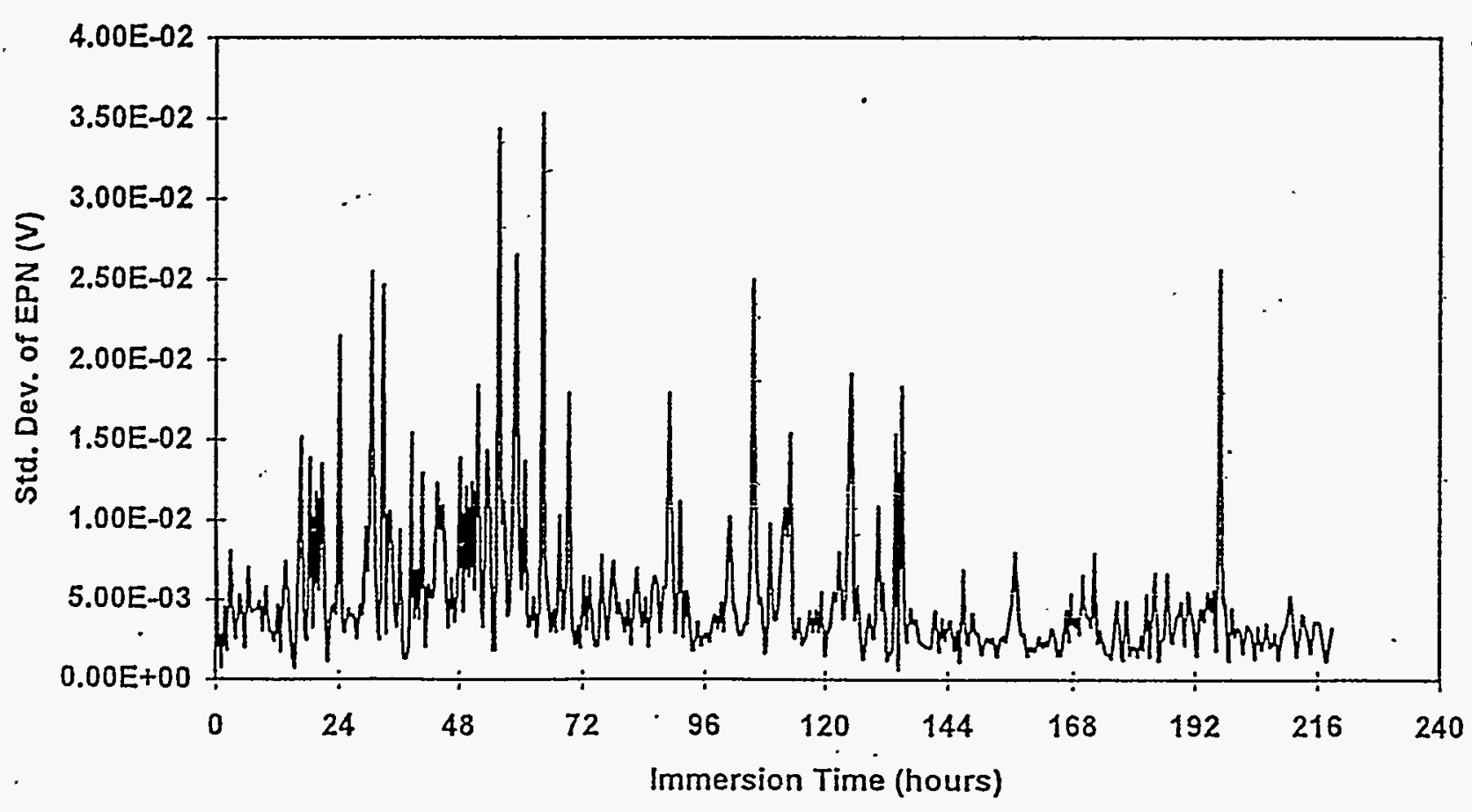

Figure 6: $\quad$ Standard Deviation of EPN versus immersion time for $A 516$ in $5 \mathrm{M}$ nitrate $+0.15 \mathrm{M}$ bydroxide solution for 220 hours. 


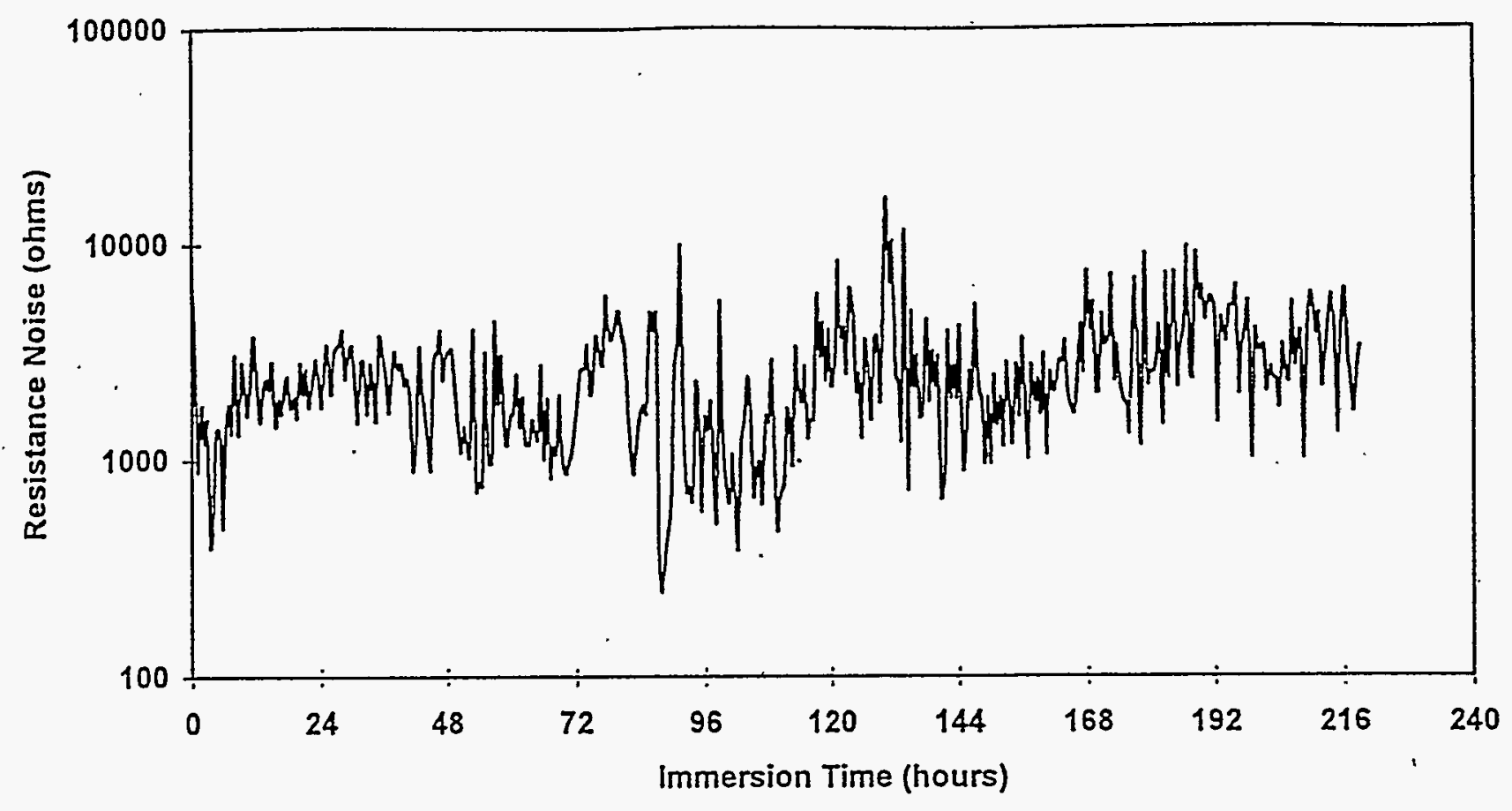

Figure 7: $\quad$ Resistance noise versus immersion time for $A 516$ in $5 \mathrm{M}$ nitrate $+0.15 \mathrm{M}$ hydroxide solution for 220 hours.

Degree of Localization - A51603

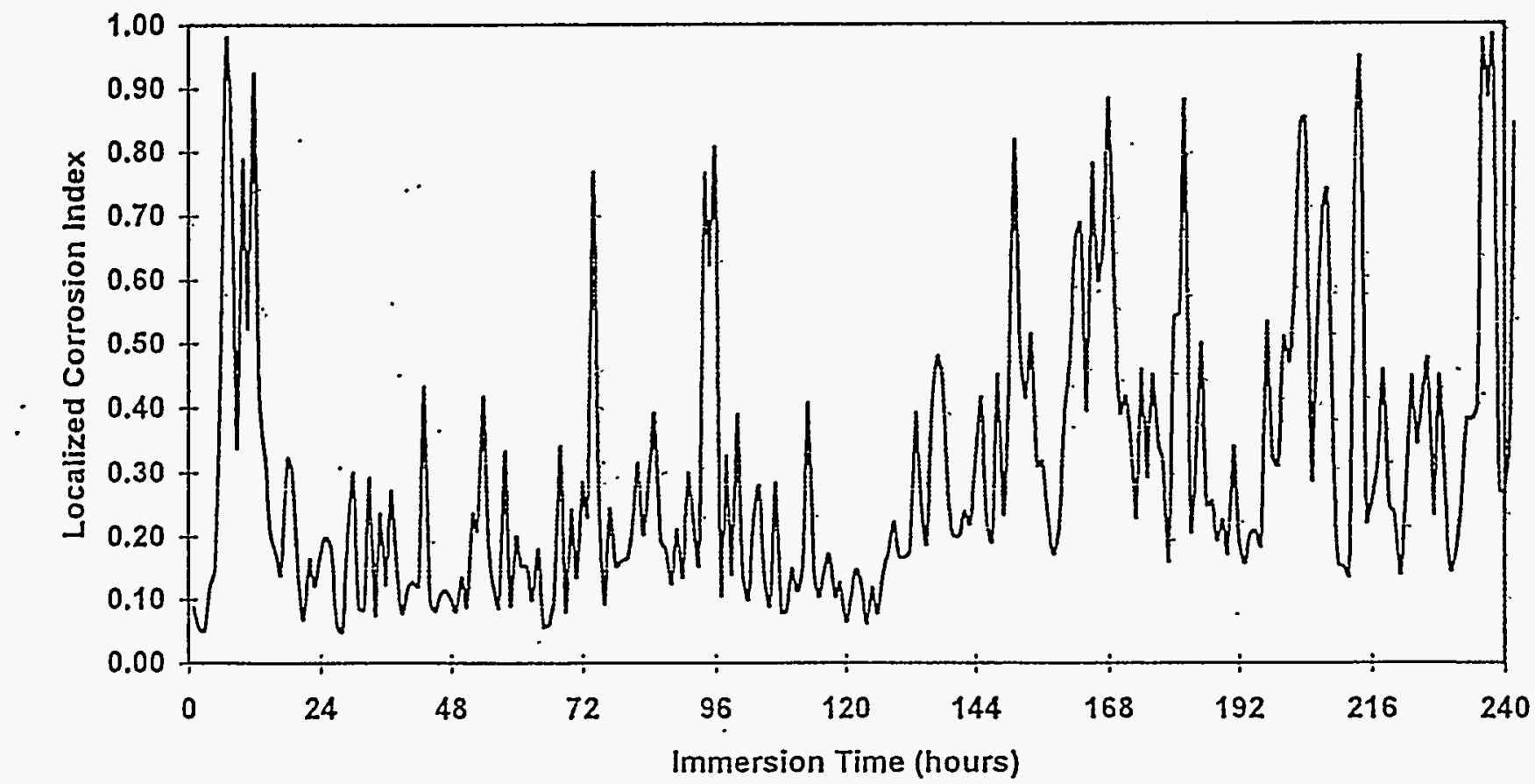

Figure 8: Degree of localization versus immersion time for $A 516$ in $5 \mathrm{M}$ nitrate $+0.15 \mathrm{M}$ hydroxide solution for 220 hours. 

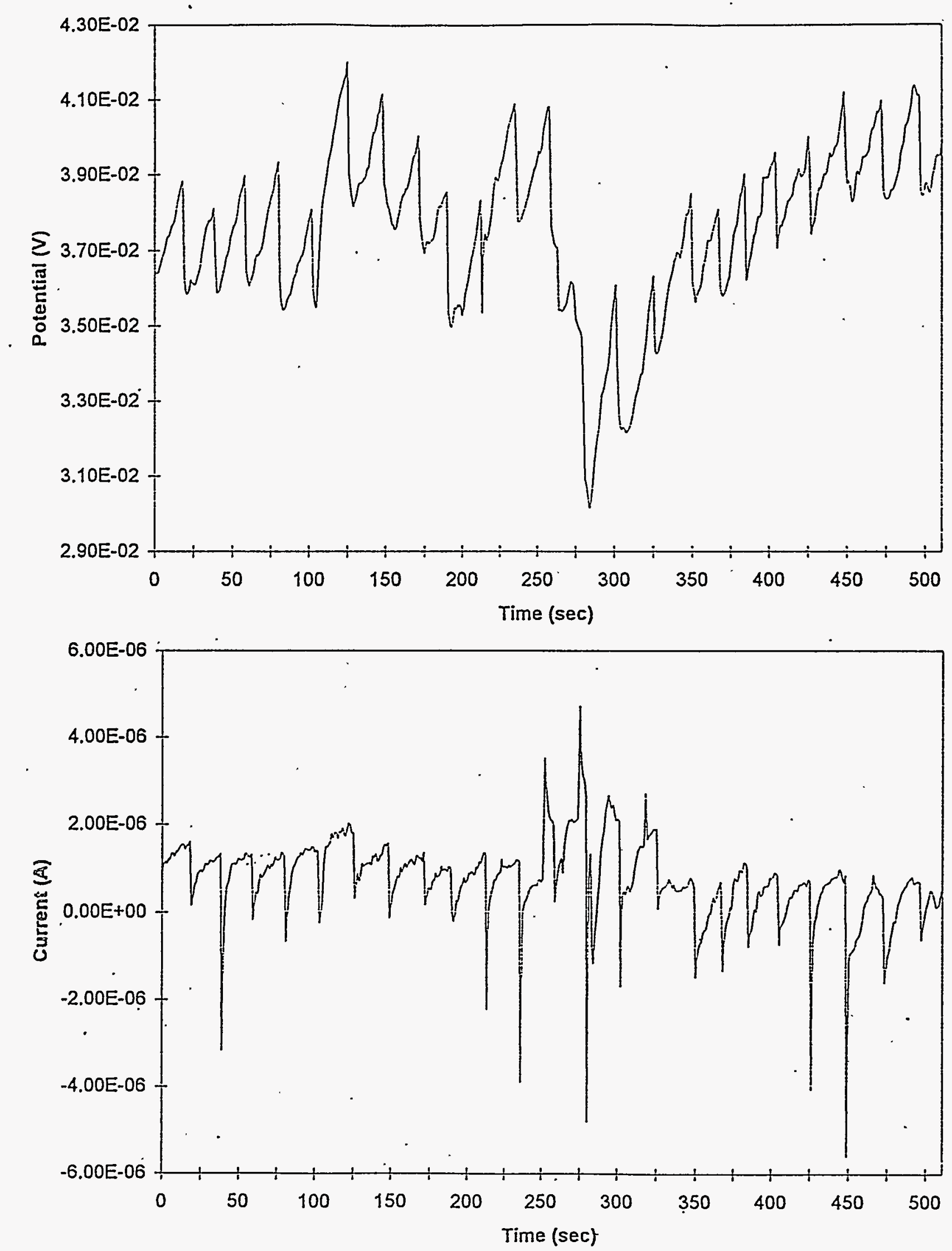

Figure 9: Detailed EPN and ECN data for $A 516$ in $5 \mathrm{M}$ nitrate $+0.15 \mathrm{M}$ hydroxide solution after approximately 95 hours of immersion. 


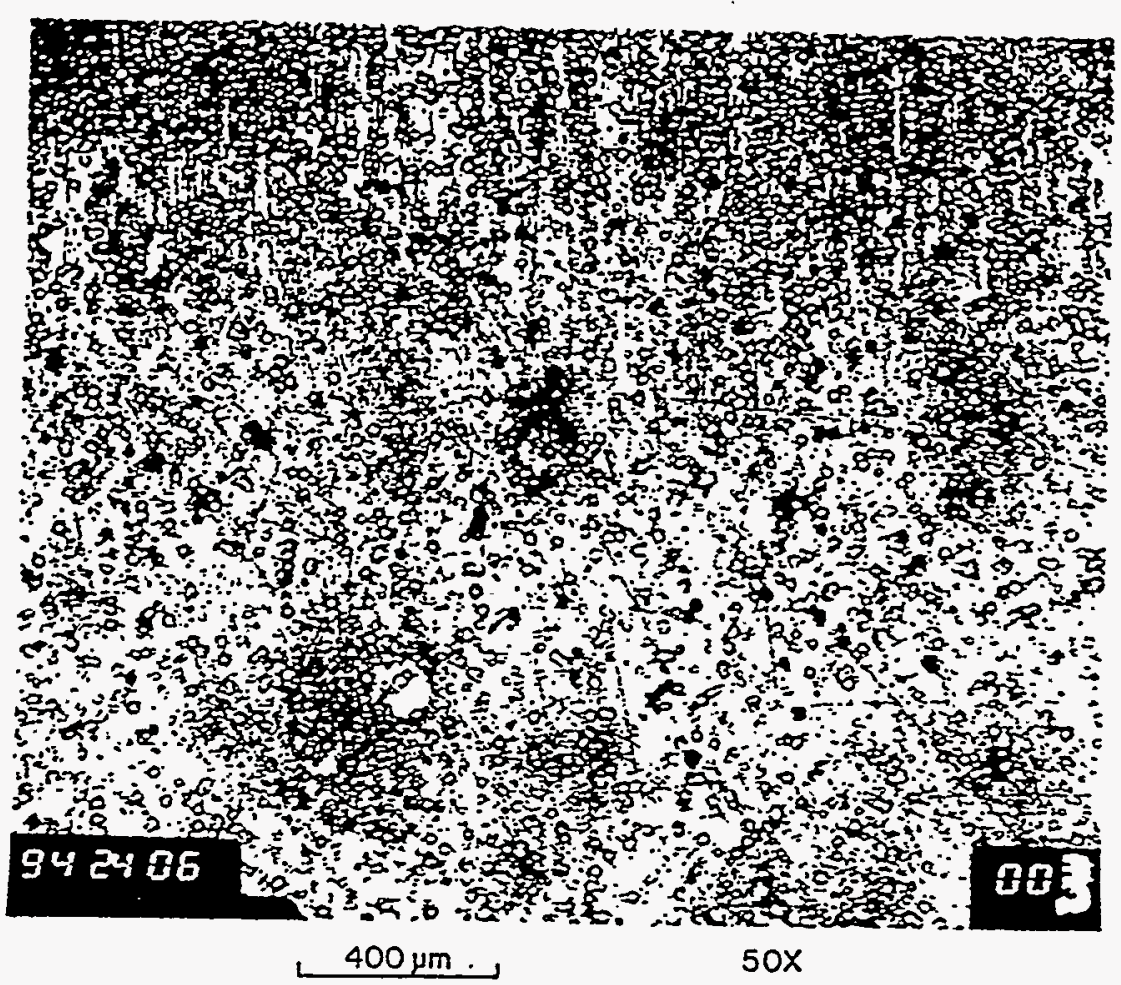

Figure 10(a): Surface of $A 516$ U-bend exposed to $5 \mathrm{M}$ nitrate $+0.15 \mathrm{M}$ hydroxide for 220 hours of immersion. Surface near solution/air interface (at top) shows higher pit density than surface below interface.

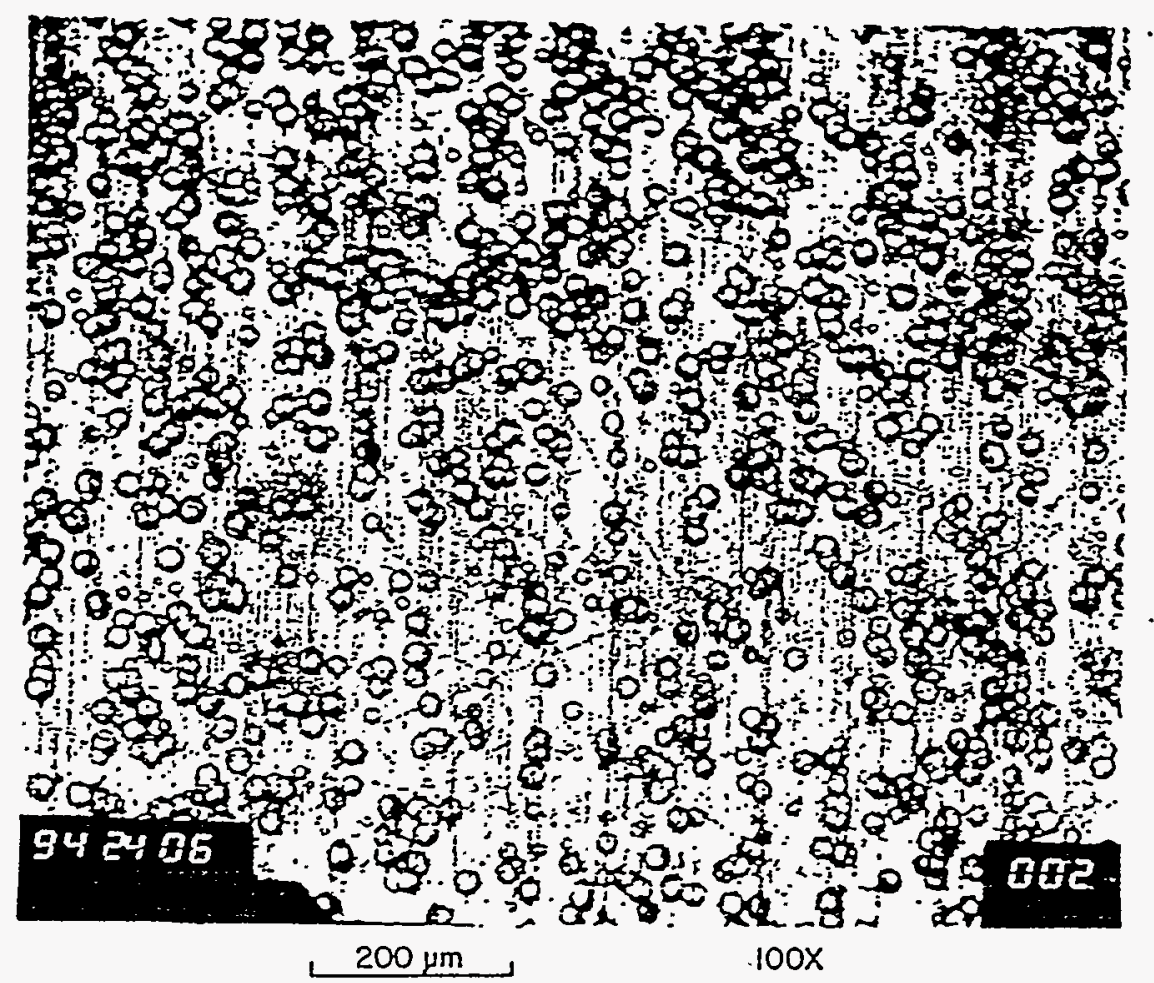

Figure 10(b): Surface of A516 U-bend exposed to $5 \mathrm{M}$ nitrate $+0.15 \mathrm{M}$ hydroxide for 220 hours of immersion. Close-up of pitting near solution interface. 


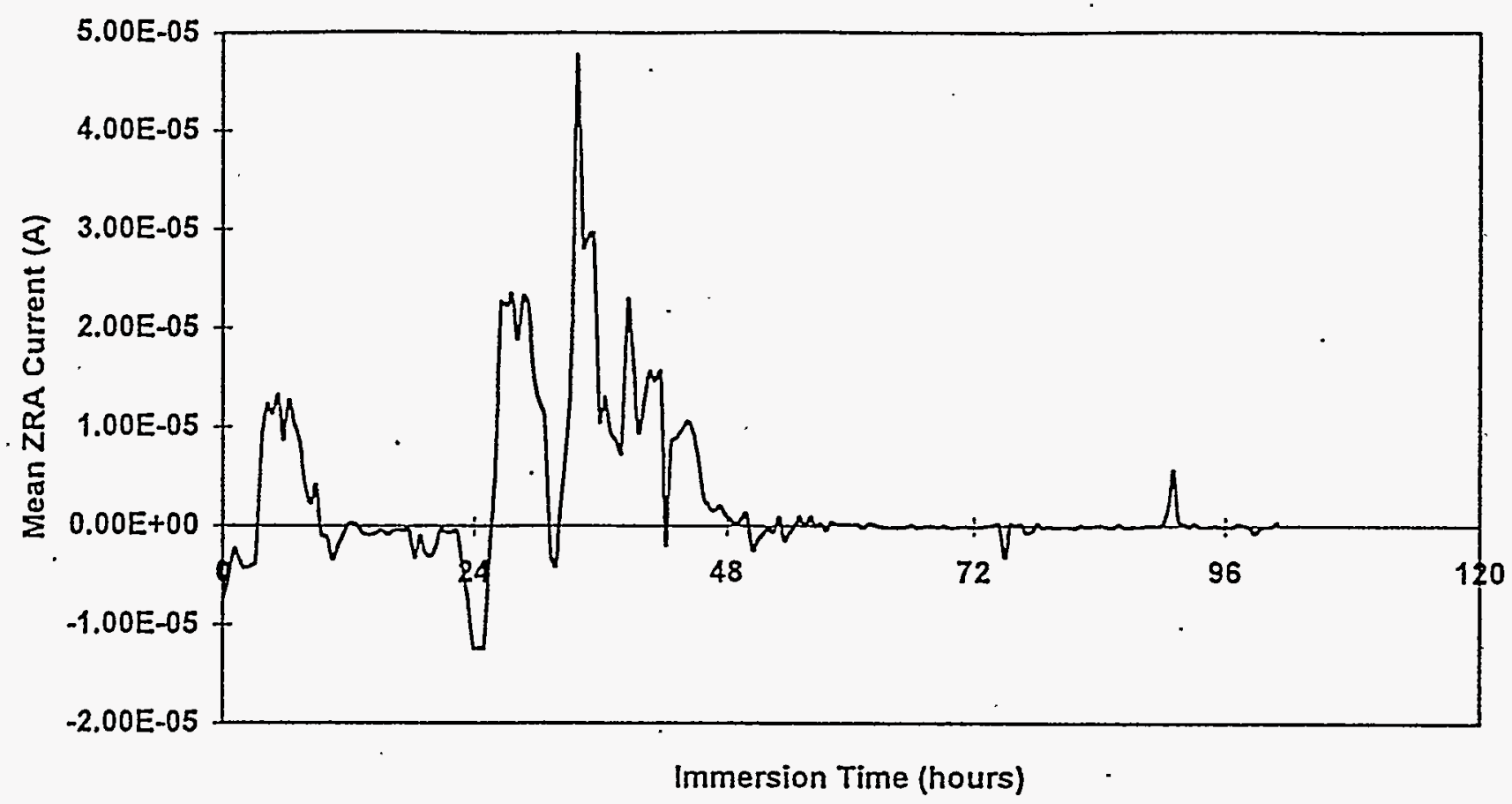

Figure 11: Mean ZRA current versus immersion time for A516 in 11M nitrate + $0.30 \mathrm{M}$ bydroxide solution for 100 hours.

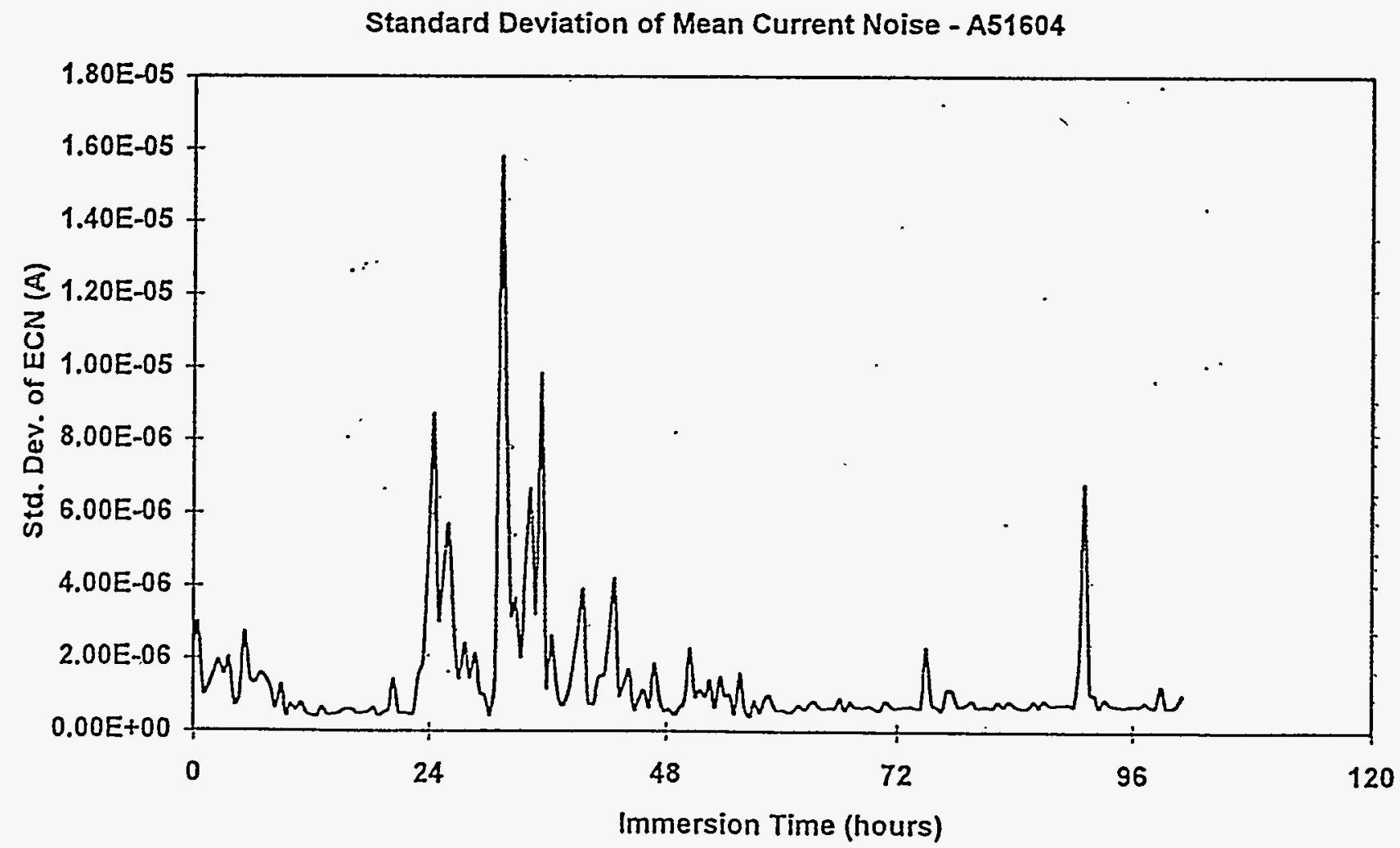

Figure 12: Standard deviation of ZRA current versus immersion time for $A 516$ in $11 \mathrm{M}$ nitrate $+0.30 \mathrm{M}$ hydroxide solution for 100 hours. 


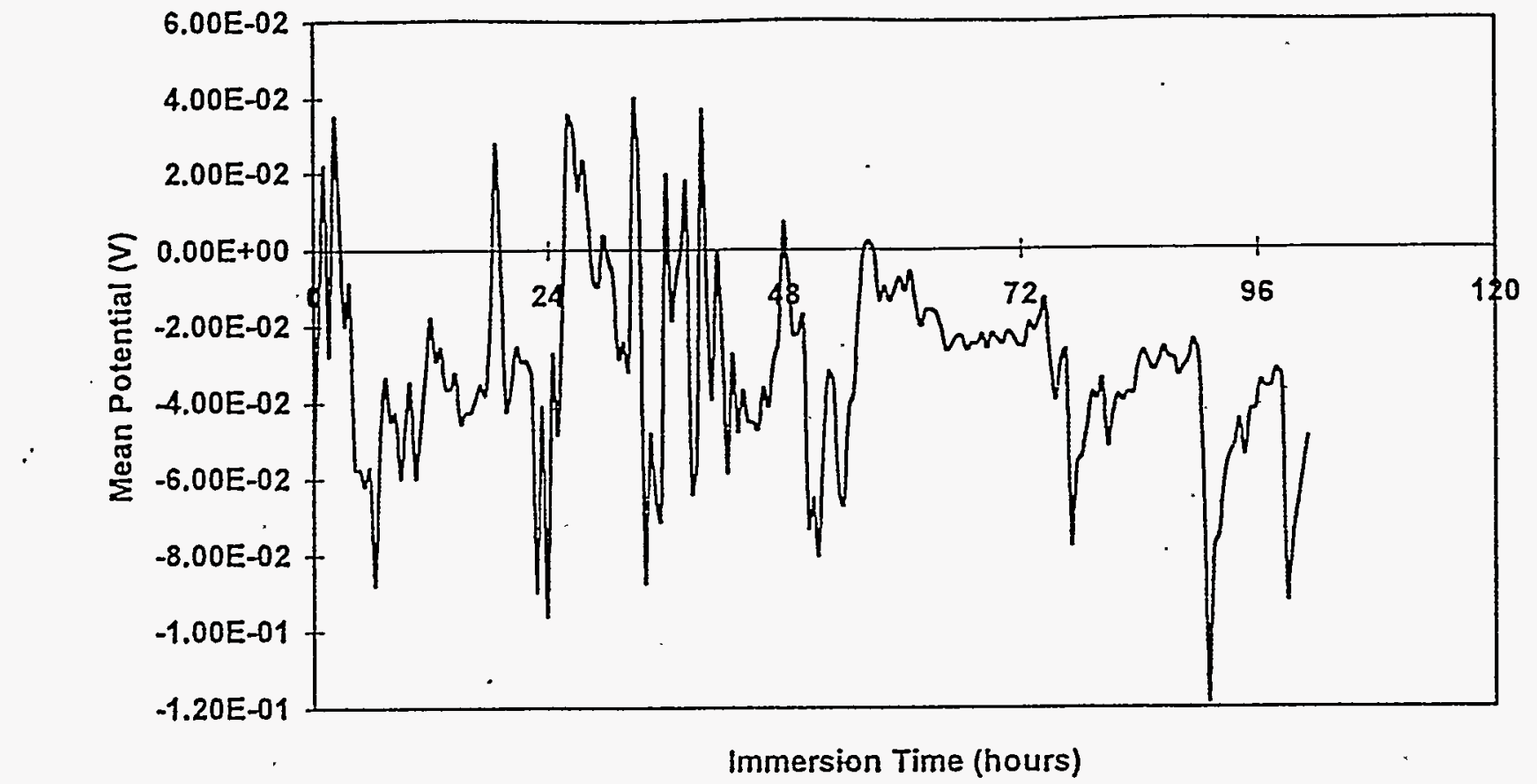

Figure 13: Mean potential with respect to reference versus immersion time for A516 in $11 \mathrm{M}$ nitrate $\div 0.30 \mathrm{M}$ hydroxide solution for 100 hours.

Standard Deviation of Mean Potential Noise - A51604

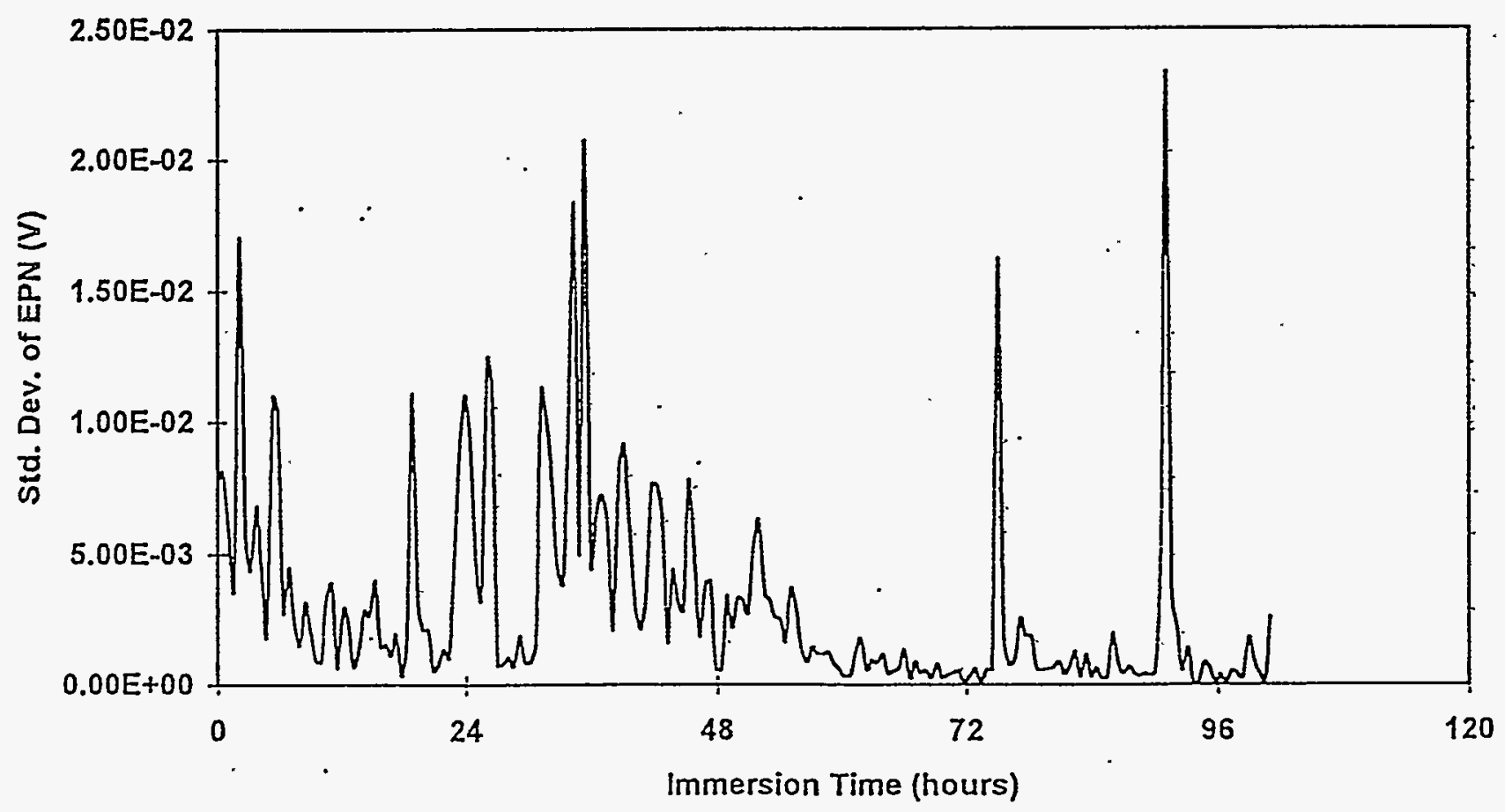

Figure 14: Standard deviation of EPN versus immersion time for A516 in 11M nitrate + $0.30 \mathrm{M}$ hydroxide solution for 100 hours. 


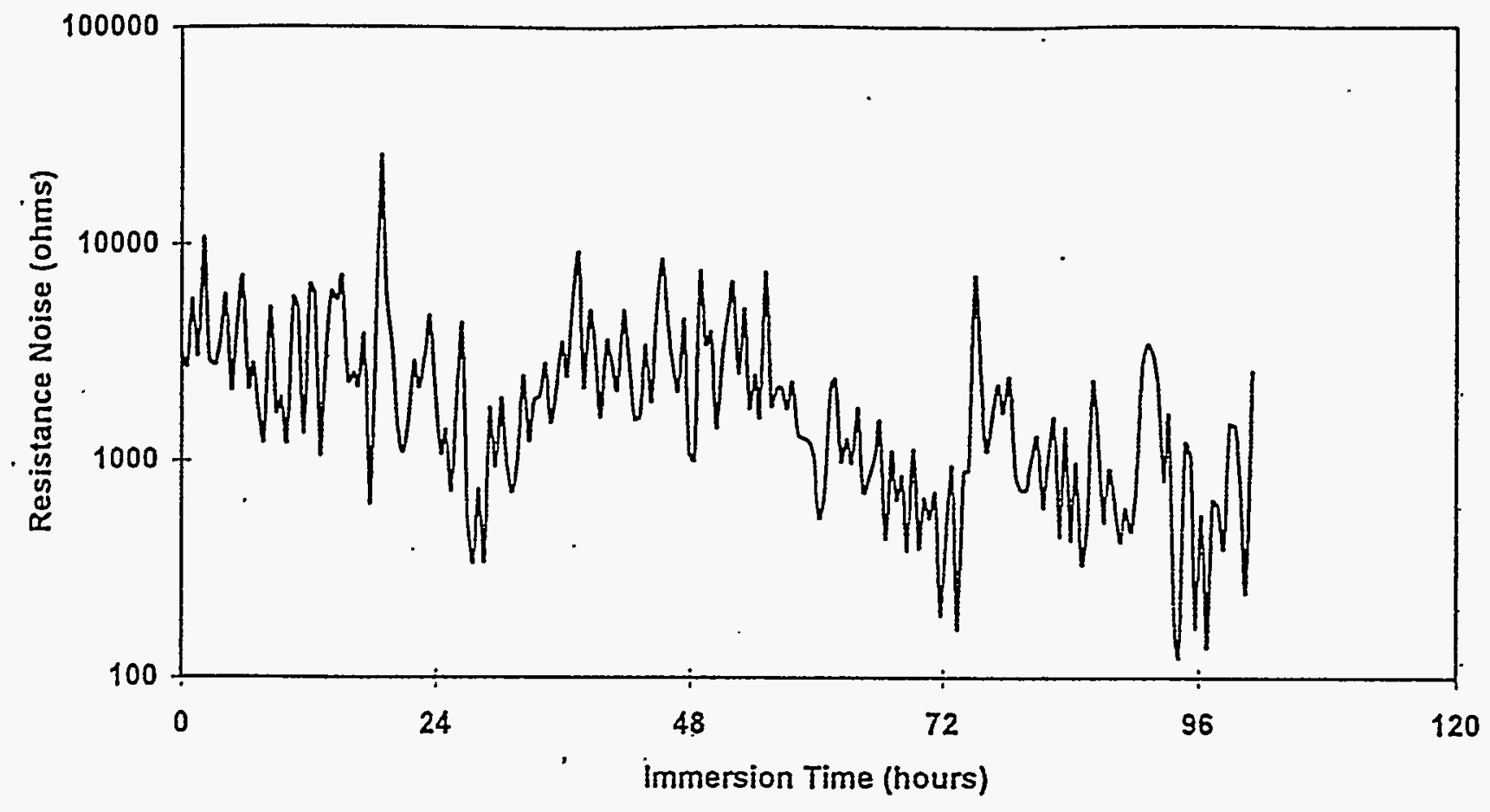

Figure 15: Resistance noise versus immersion time for A516 in $11 \mathrm{M}$ nitrate $+0.30 \mathrm{M}$ hydroxide solution for 100 hours.

Degree of Localization - A51604

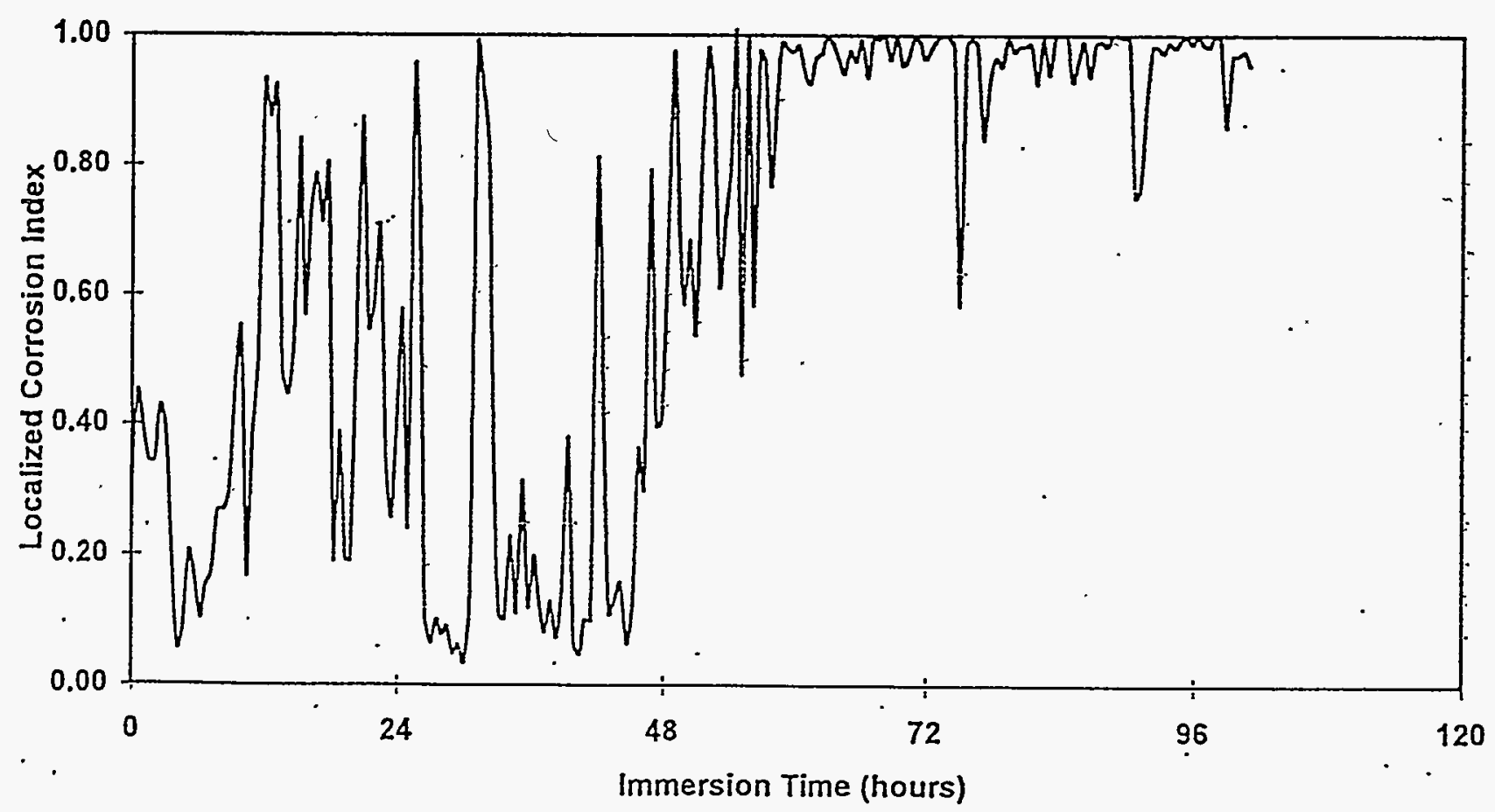

Figure 16: Degree of localization versus immersion time for $\mathrm{A} 516$ in $11 \mathrm{M}$ nitrate $+0.30 \mathrm{M}$ hydroxide solution for 100 hours. 

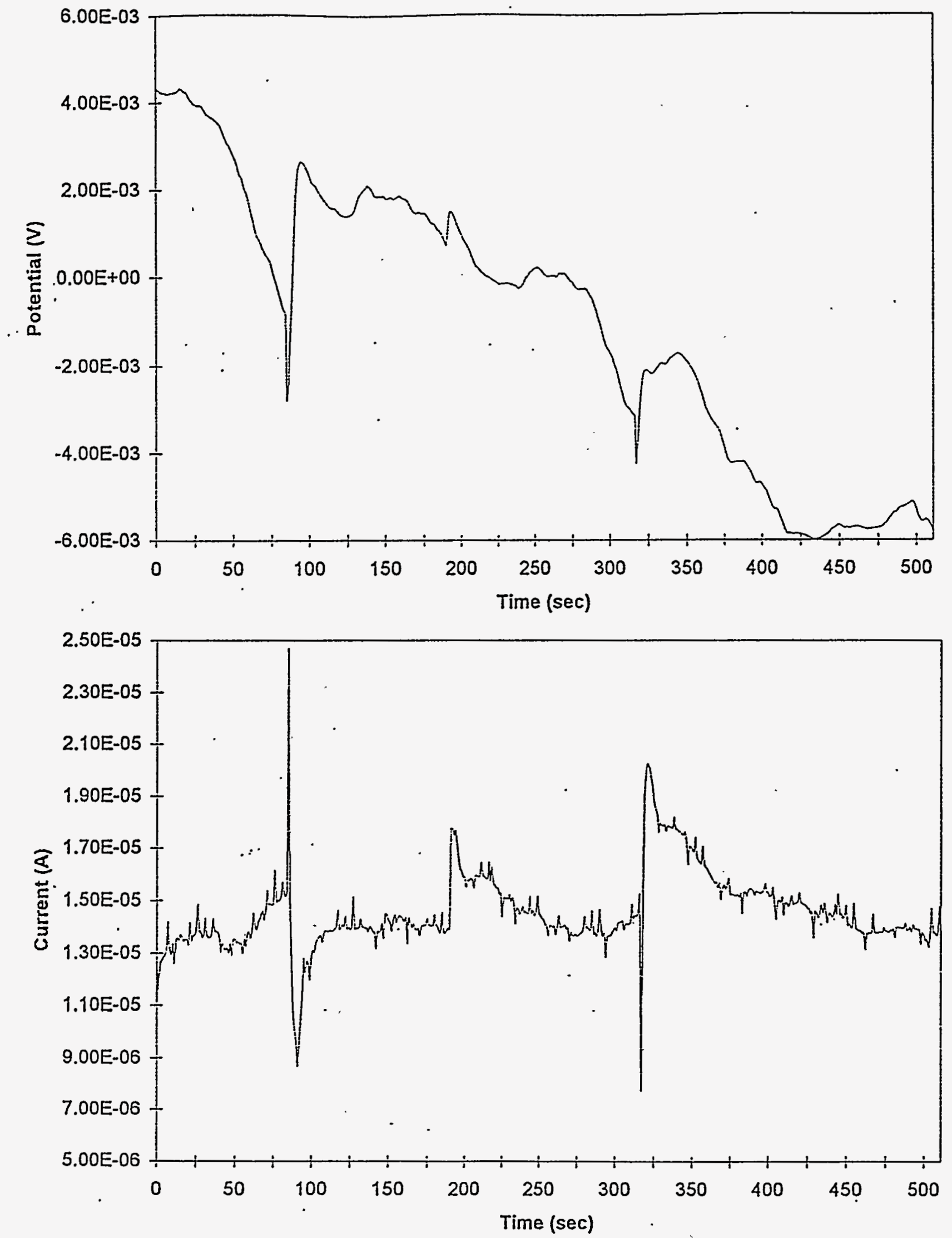

Figure 17: Detailed EPN and ECN data for A516 in $11 \mathrm{M}$ nitrate + $0.30 \mathrm{M}$ hydroxide solution after approximately 41 hours of immersion. 

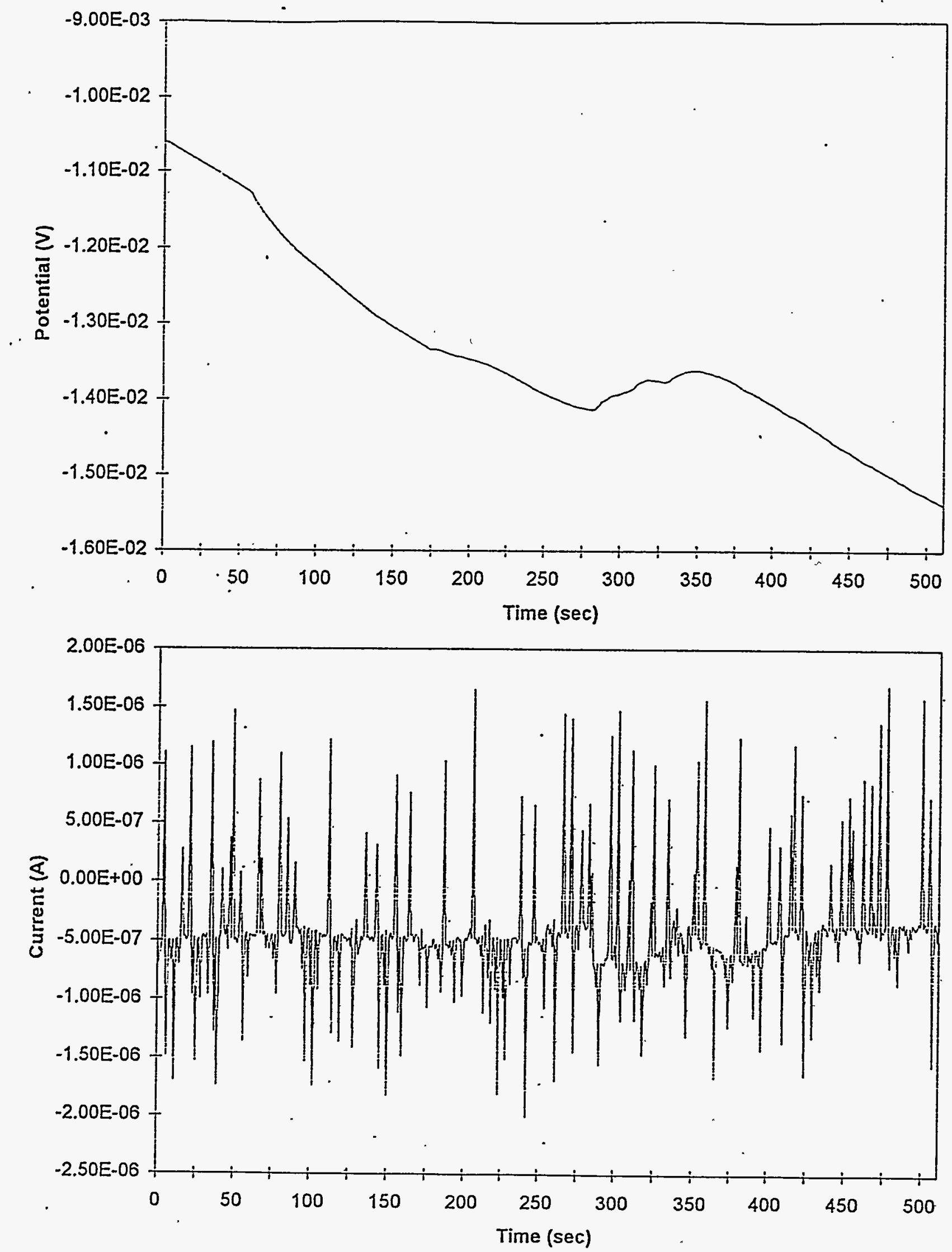

Figure 18: $\quad$ Detailed EPN and ECN data for A516 in $11 \mathrm{M}$ nitrate $+0.30 \mathrm{M}$ hydroxide solution after approximately 58 hours of immersion. 


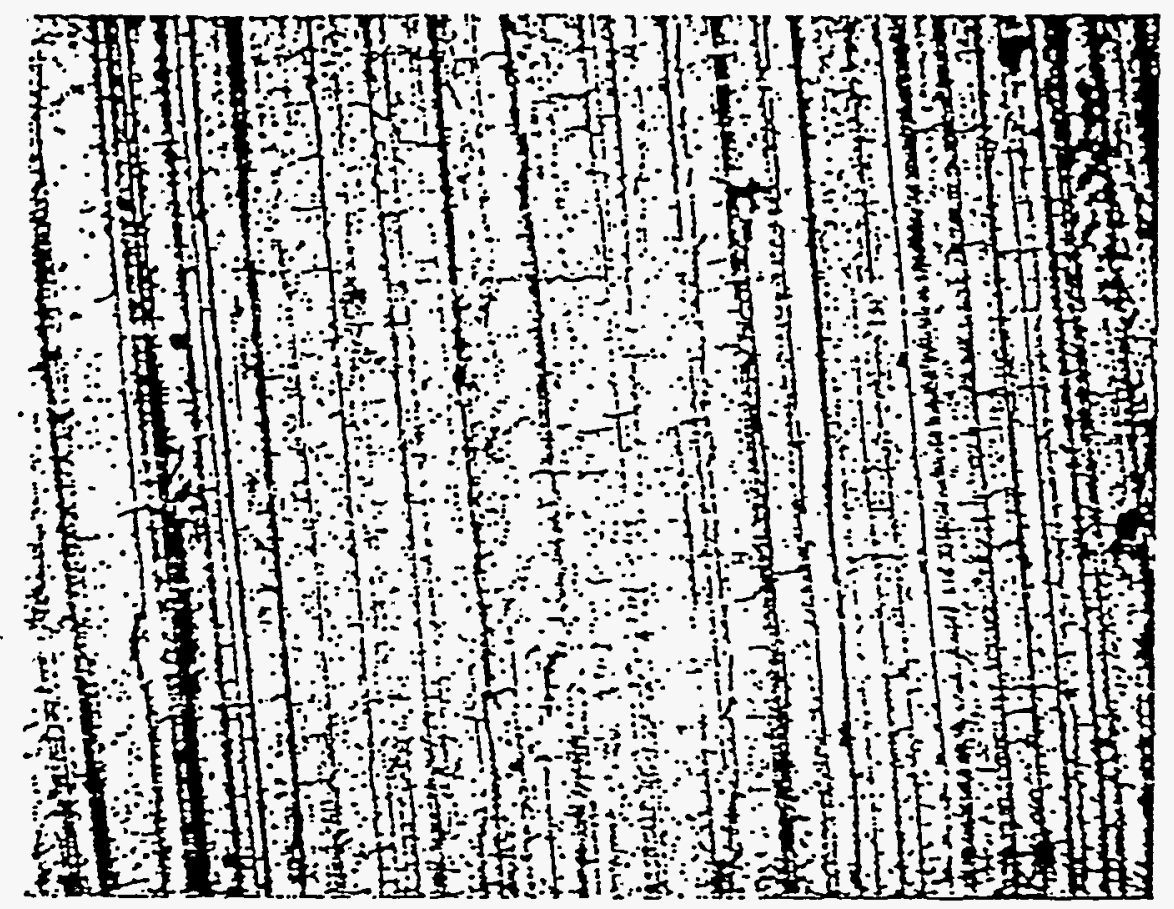

Figure 19(a): Low magnification SEM micrograph of region near maximum stress on A516 U-bend in $11 M$ nitrate $\div$ $0.30 \mathrm{M}$ hydroxide solution after 100 hours of immersion.

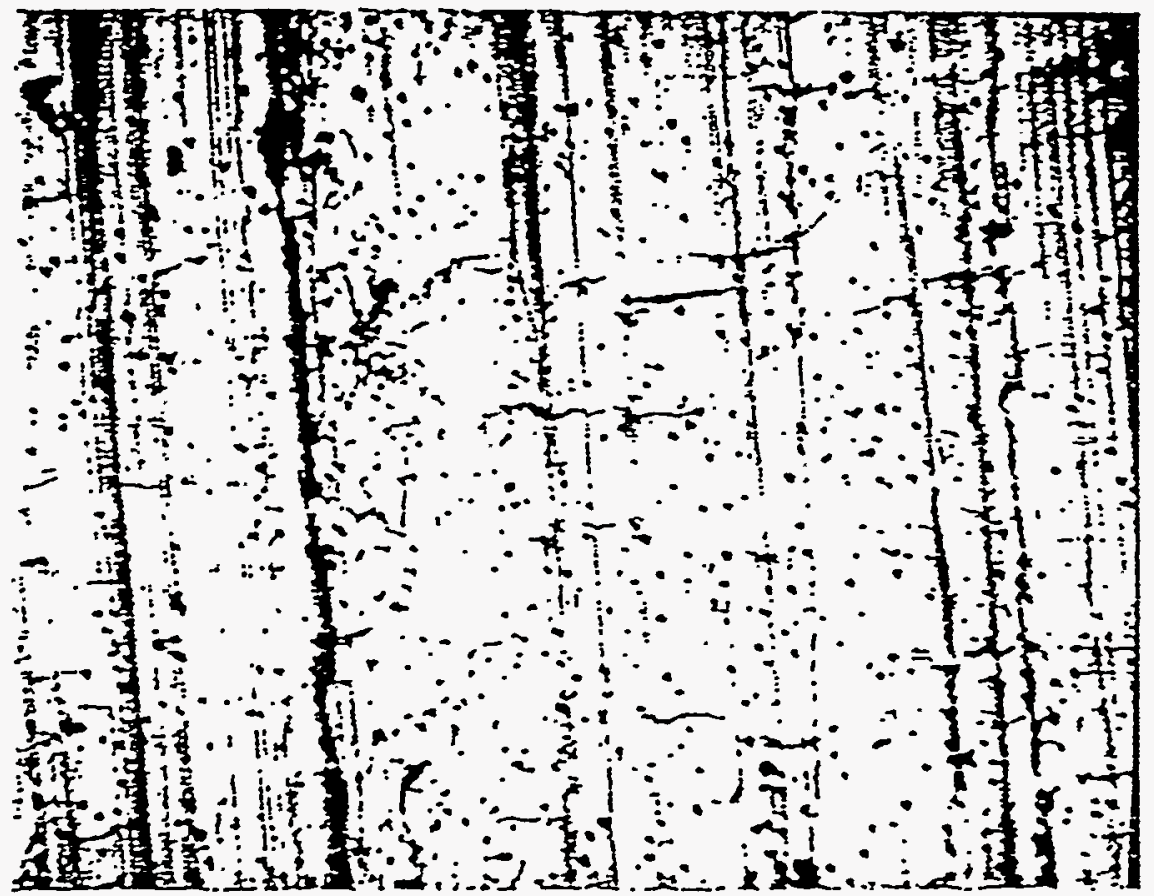

Figure 19(b): Higher magnification SEM micrograph of micro cracking and pitting near region of maximum stress on A516 U-bend in $11 \mathrm{M}$ nitrate $+0.30 \mathrm{M}$ hydroxide solution after 100 hours of immersion. 


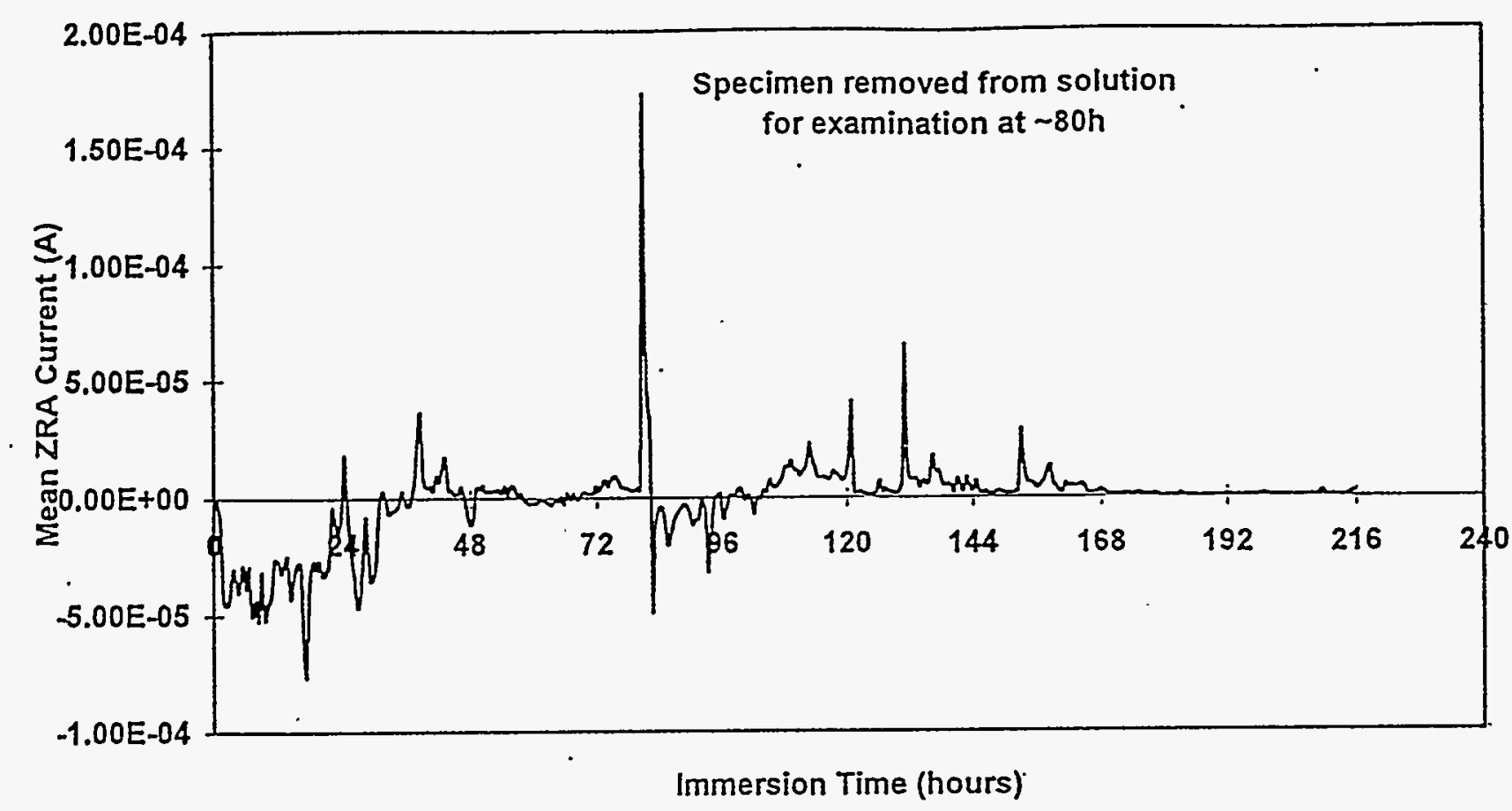

Figure 20: $\quad$ Mean ZRA current versus immersion time for A537 in $5 \mathrm{M}$ nitrate $\div 0.15 \mathrm{M}$ hydroxide solution for 2.16 hours.

\section{Standard Deviation of Mean Current Noise - A53704}

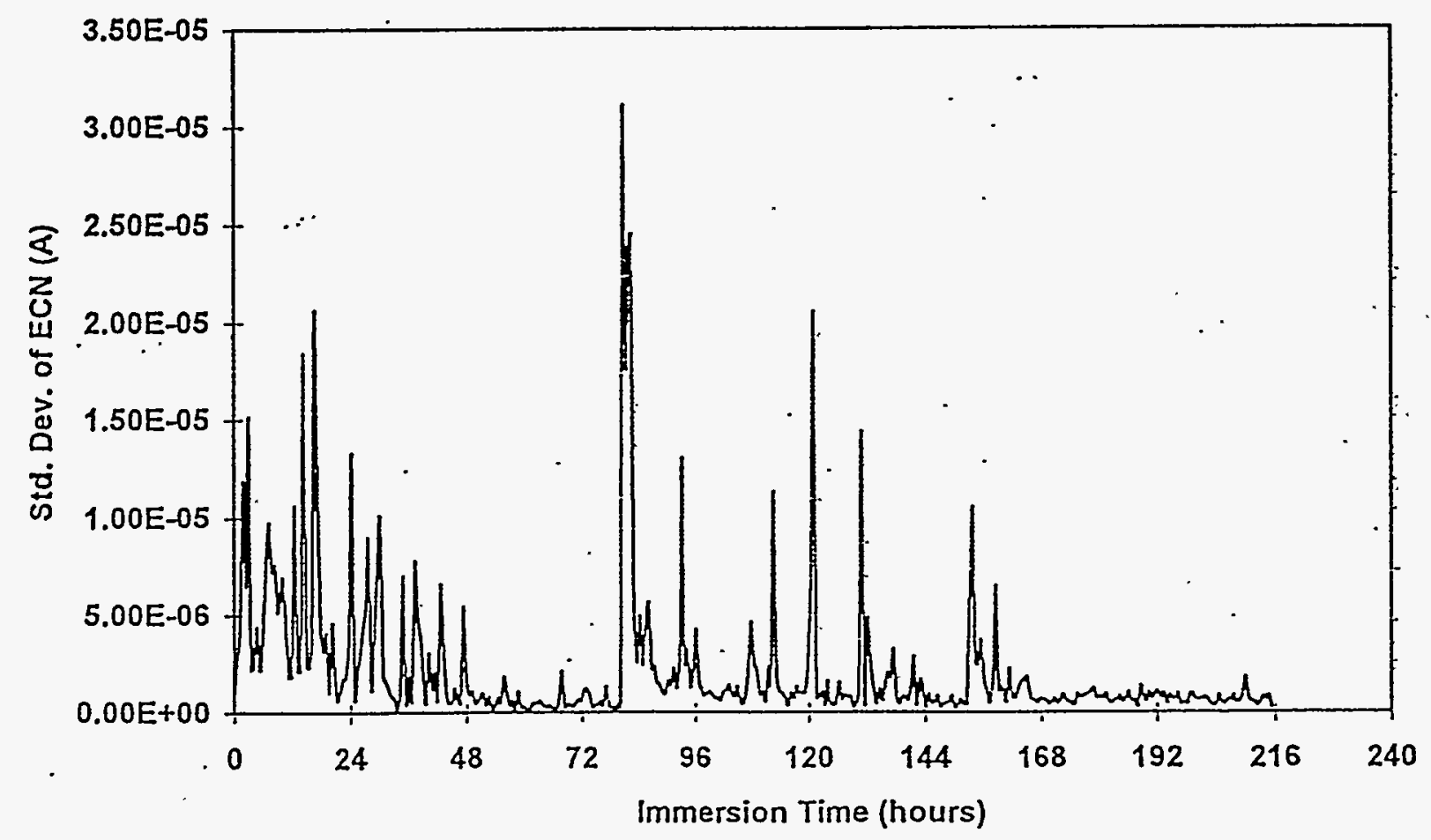

Figure 21: Standard deviation of ZRA current versus immersion time for A537 in $5 \mathrm{M}$ nitrate $+0.15 \mathrm{M}$ hydroxide solution for 216 hours: : 


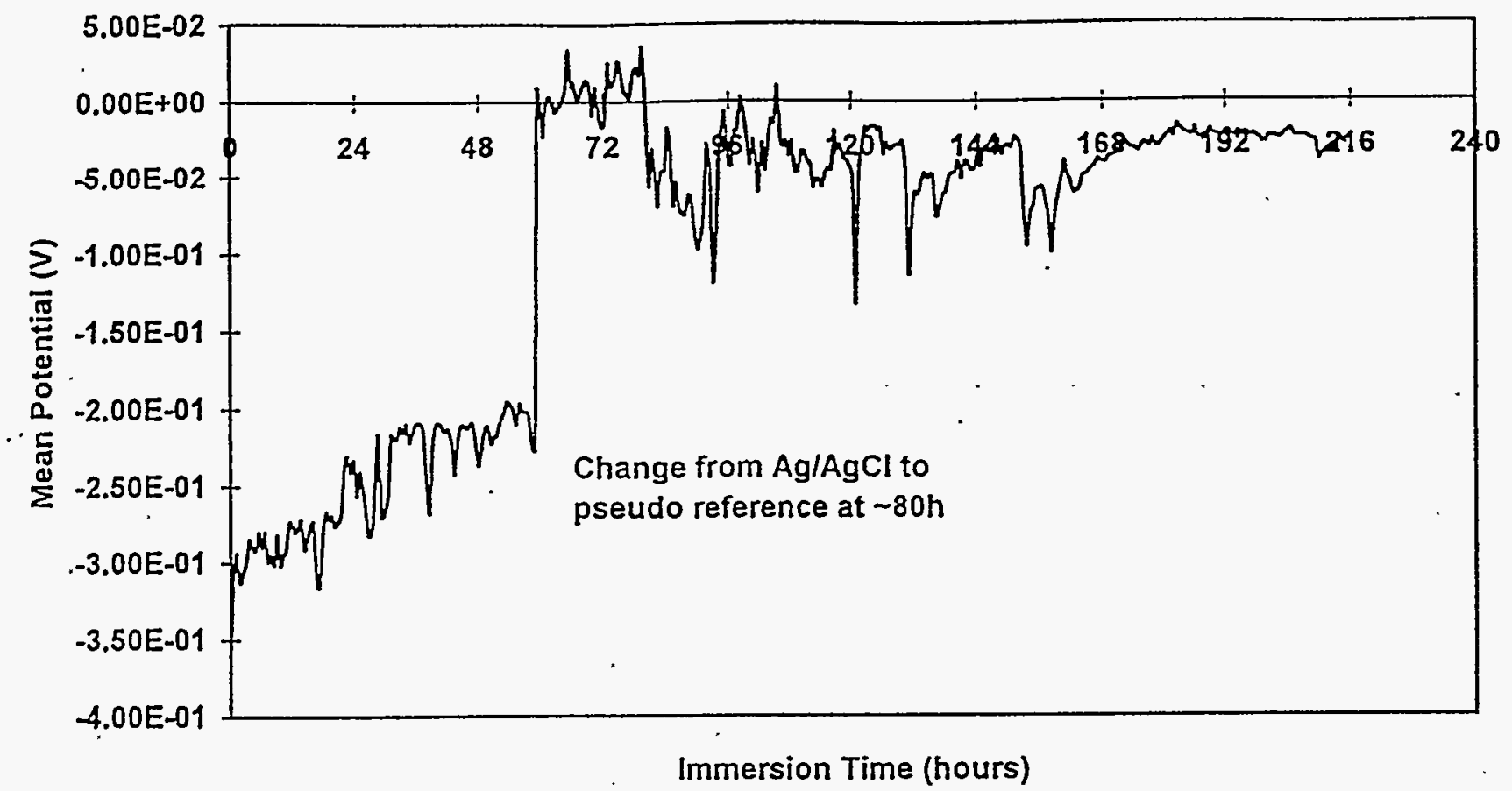

Figure 22: Mean potential with respect to reference versus immersion time for $A 537$ in $5 \mathrm{M}$ nitrate $+0.15 \mathrm{M}$ hydroxide solution for 216 hours.

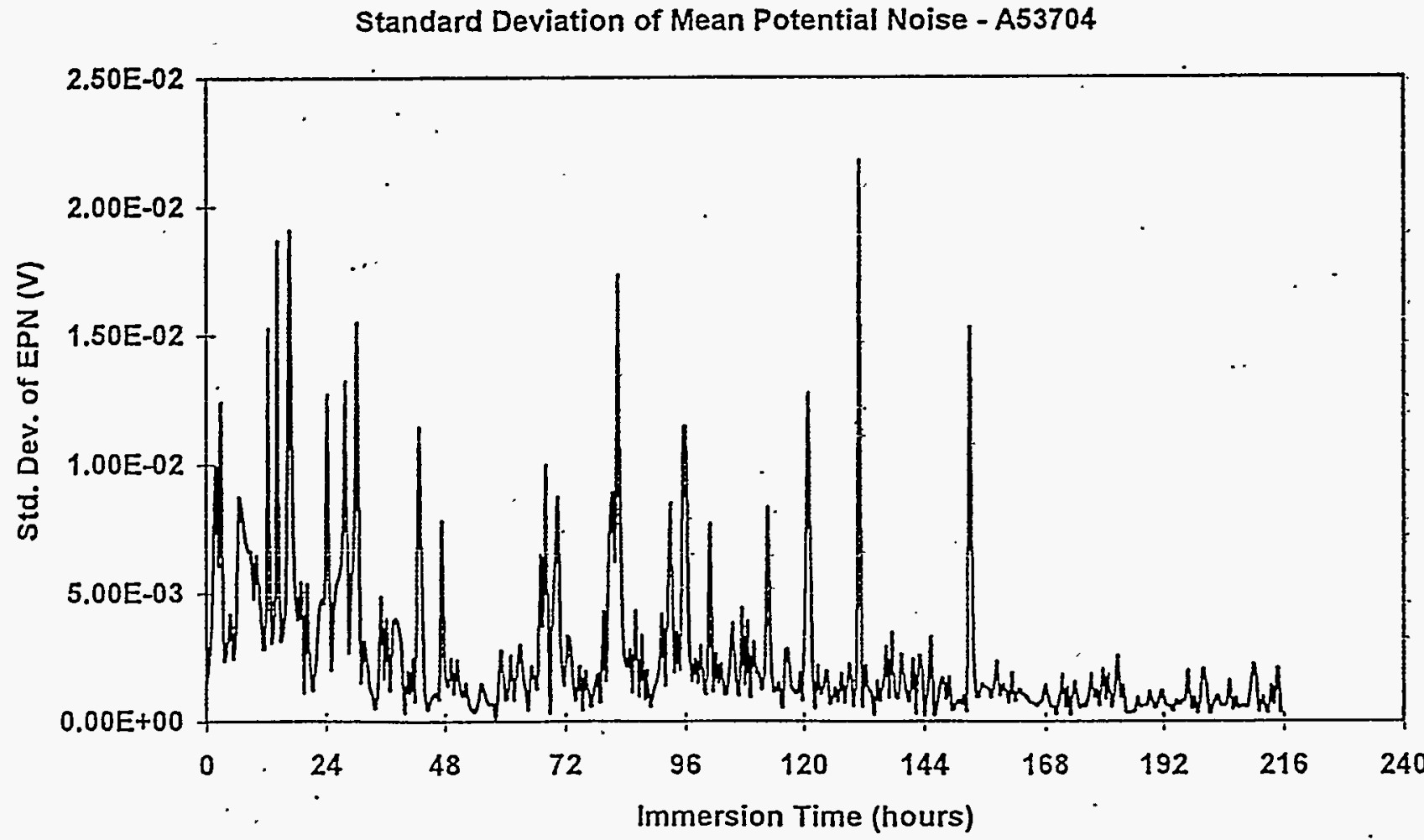

Figure 23: $\quad$ Standard deviation of EPN versus immersion time for $A 537$ in $5 \mathrm{M}$ nitrate $+0.15 \mathrm{M}$ hydroxide solution for 216 bours. 


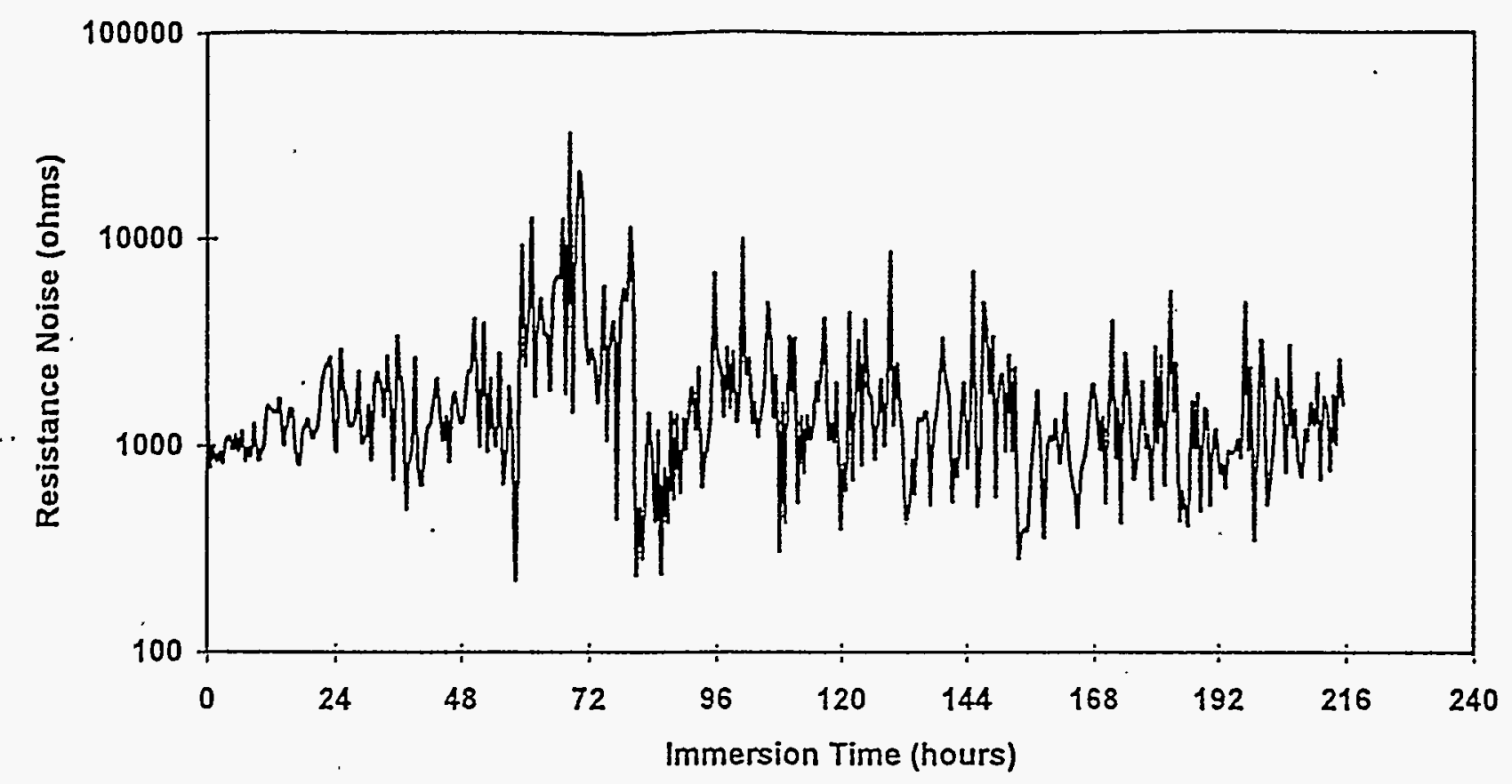

Figure 24: Resistance noise versus immersion time for A537 in 5M nitrate $+0.15 M$ hydroxide solution for 216 hours.

\section{Degree of Localization - A53704}

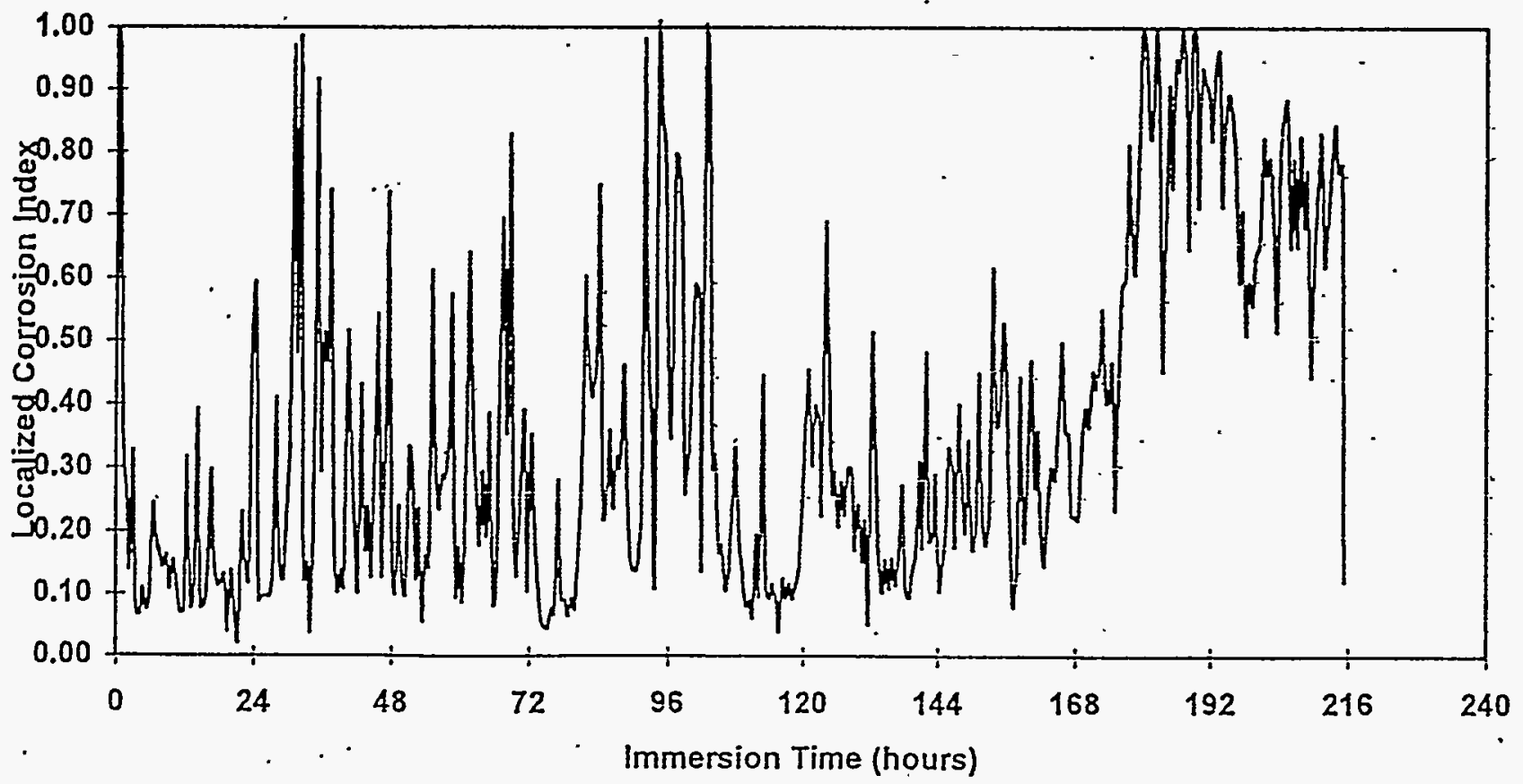

Figure 25: Degree of localization versus immersion time for $A 537$ in $5 \mathrm{M}$ nitrate $+0.15 \mathrm{M}$ bydroxide solution for 216 bours. 

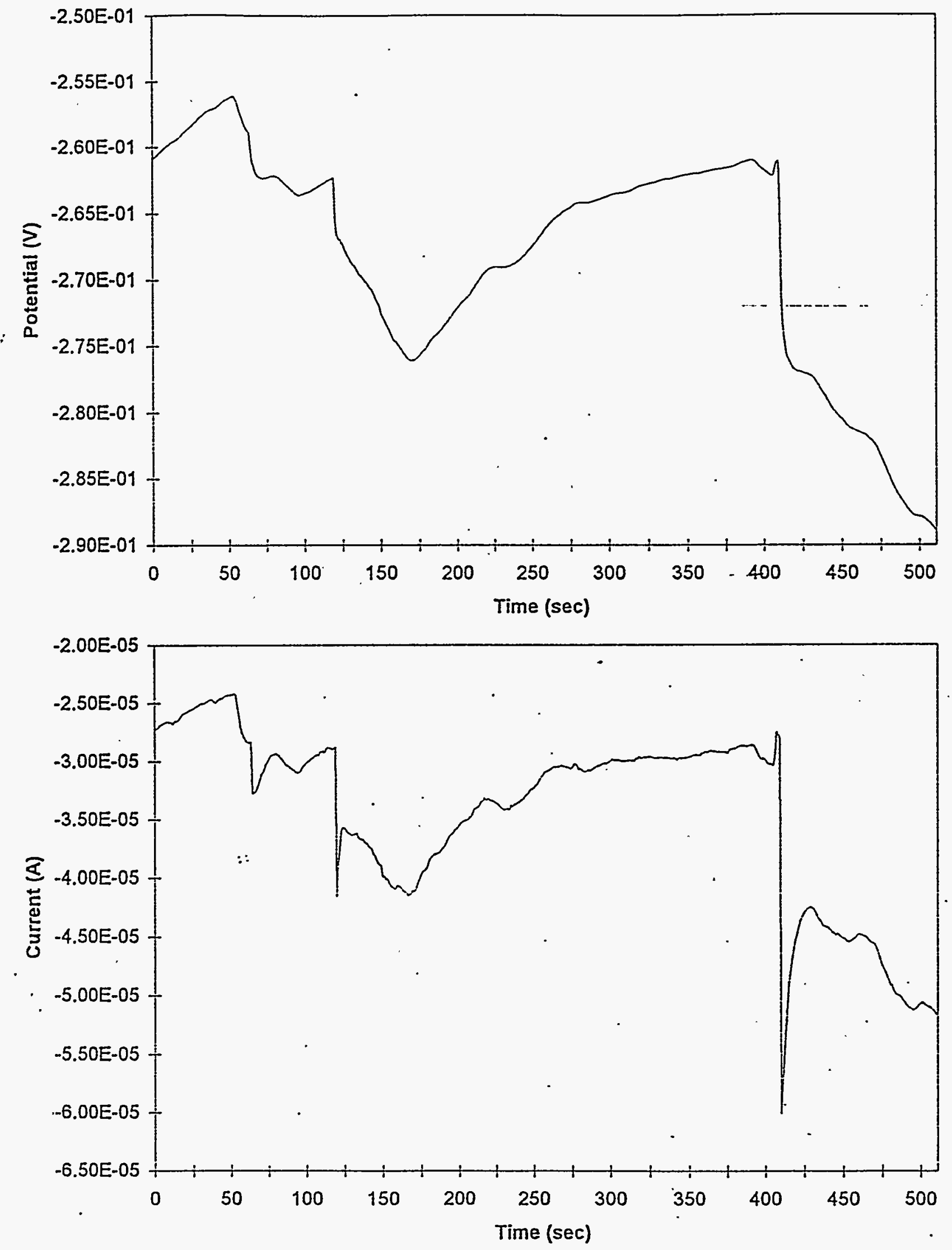

Figure 26: Detailed EPN and ECN data for A537 in 5M nitrate + 0.15M hydroxide solution after approximately 30 bours of immersion. 


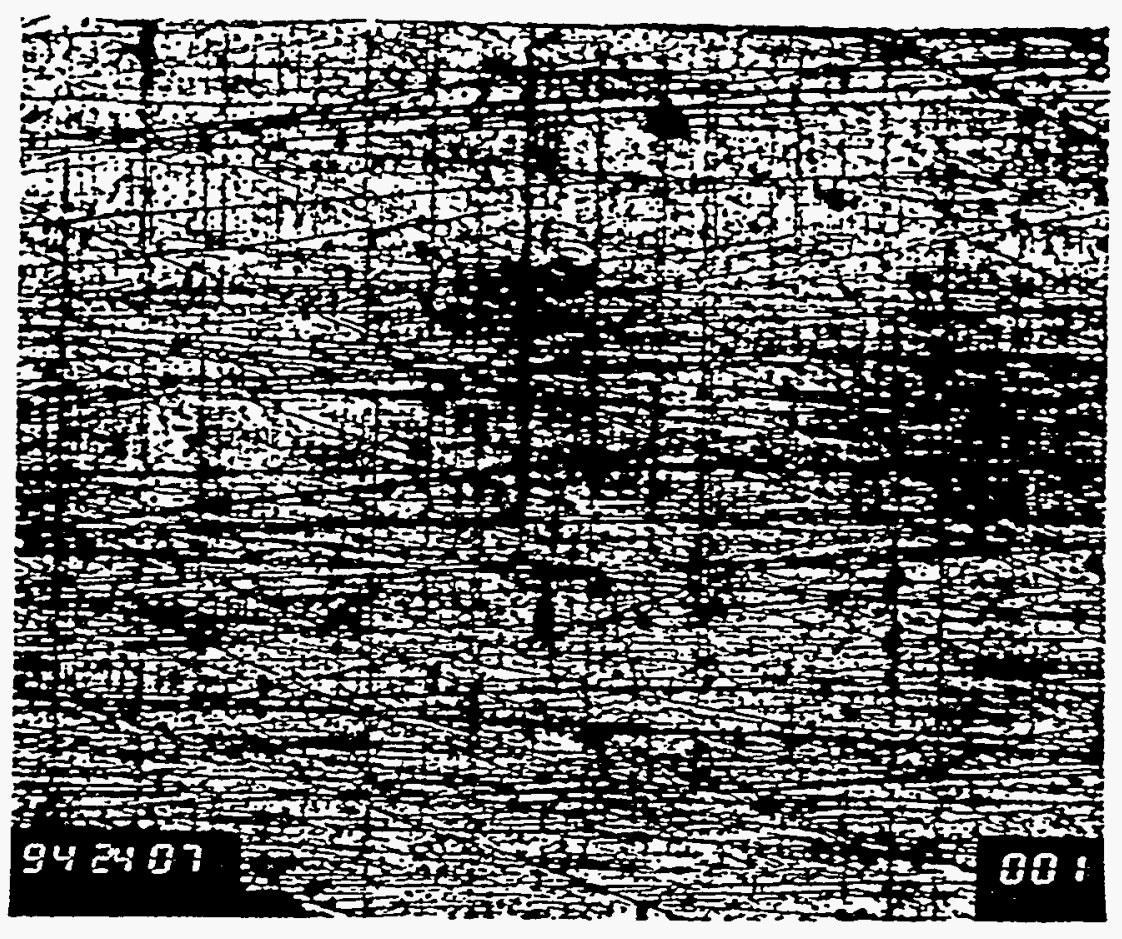

$$
400 \mu \mathrm{m}, 50 \mathrm{x}
$$

Figure 27(a): Optical micrograph of solution/air interface on surface of A537 U-bend in $5 \mathrm{M}$ nitrate $\div 0.15 \mathrm{M}$ hydroxide . solution after 216 hours of immersion.

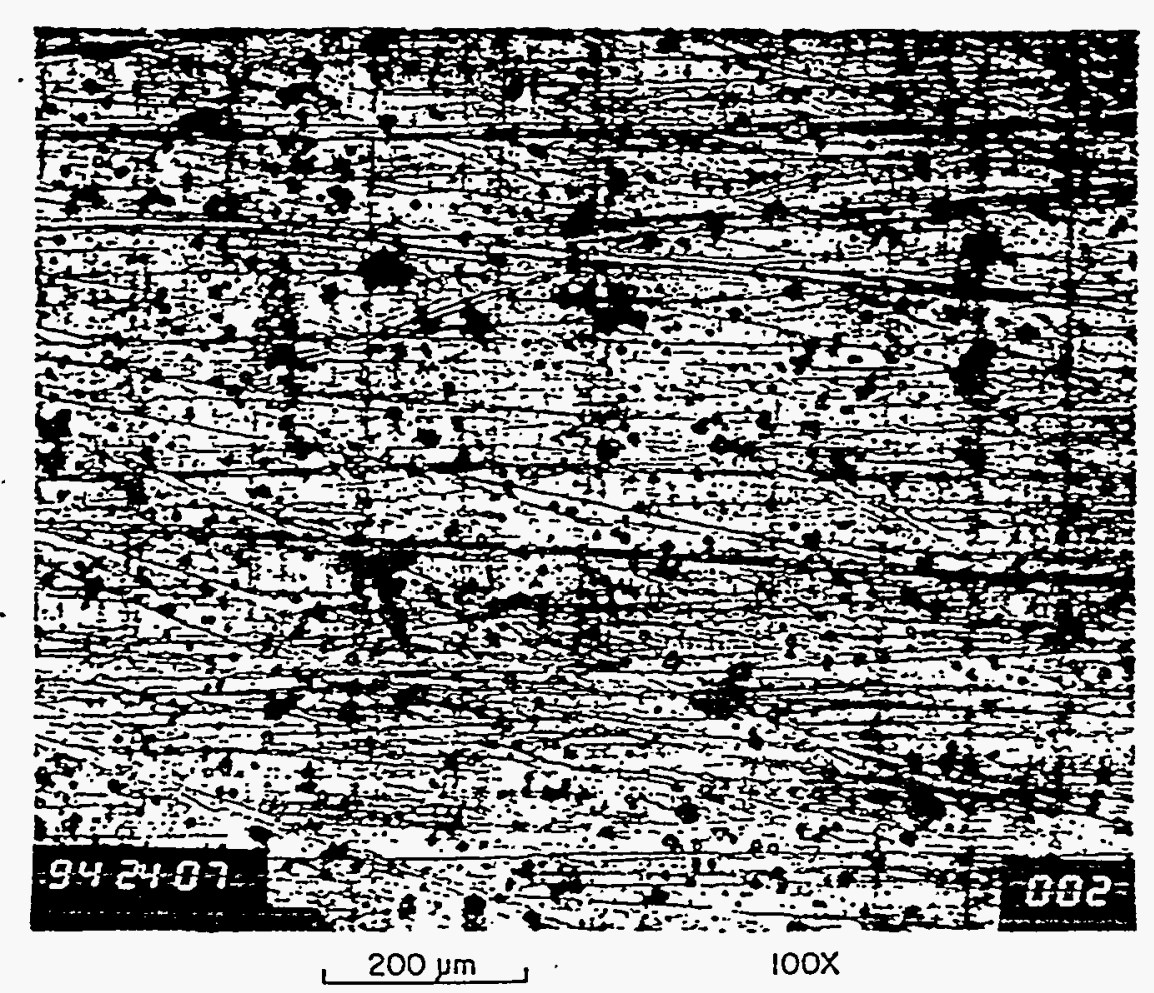

Figure 27(b): Higher magnification optical micrograph of pitting near solution/air interface on surface of A537 U-bend in $5 \mathrm{M}$ nitrate $+0.15 \mathrm{M}$ hydroxide solution after 216 hours of immersion. 